\title{
RECEIVED
}

JUN 271996

OSTI

\section{Hydrogen and Oxygen}

Concentrations in IXCs:

\section{A Compilation}
L. M. Liljegren
G. T. Terrones
P. K. Melethil

June 1996

Prepared for

the U.S. Department of Energy

Contract DE-AC06-76RLO 1830

Pacific Northwest National Laboratory

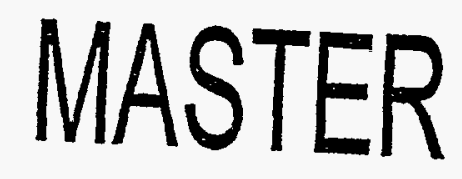

Operated for the U.S. Department of Energy

by Battelle 


\title{
DISCLAIMER
}

This report was prepared as an account of work sponsored by an agency of the United States Government. Neither the United States Government nor any agency thereof, nor Battelle Memorial Institute, nor any of their employees, makes any warranty, expressed or implied, or assumes any legal liability or responsibility for the accuracy, completeness, or usefulness of any information, apparatus, product, or process disclosed, or represents that its use would not infringe privately owned rights. Reference herein to any specific commercial product, process, or service by trade name, trademark, manufacturer, or otherwise does not necessarily constitute or imply its endorsement, recommendation, or favoring by the United States Government or any agency thereof, or Battelle Memorial institute. The views and opinions of authors expressed herein do not necessarily state or reflect those of the United States Government or any agency thereof.

\author{
PACIFIC NORTHWEST LABORATORY \\ operated by \\ BATTELLE MEMORIAL INSTITUTE \\ for the \\ UNITED STATES DEPARTMENT OF ENERGY \\ under Contract DE-AC06-76RLO 1830
}




\title{
Hydrogen and Oxygen Concentrations in IXCs: A Compilation
}

\author{
L. M. Liljegren \\ G. T. Terrones \\ P. K. Melethil
}

June 1996

Prepared for the U.S. Department of Energy under Contract DE-AC06-76RLO 1830

Pacific Northwest National Laboratory

Richland, Washington 99352 


\title{
Estimate of Hydrogen and Oxygen Concentrations in IXCs
}

\author{
L.M. Liljegren, G.T. Terrones, P.K. Melethil
}

June 1996

\section{Introduction}

The analyses to predict the hydrogen and oxygen concentrations in LXMs and IXCs contained in the K-East and K-West Basins at the Hanford site were performed by PNNL personnel during FY-95. Peer reviewed results were provided to WHC as client limited reports. The results of PNL-DX-0019 are being used to support assessments required for operation of the basins. Consequently, this report is being cleared for public dissemination. To facilitate evaluation by the public, all internal reports cited directly by PNL-IX-0019 are also included as attachments.

Four reports and two internal letters are included as attachments to this document. They are compiled in chronological order. With one exception, the contents have not been modified from their original form. The exception is the disclaimer limiting the results to internal use has been eliminated. To allow traceability to project files, the original internal project numbering system is provided. The documents included are:

Estimate of Hydrogen Concentration in KW-14, L.M. Liljegren, PNL-IX-IR-006, 1/31/95.

Estimate of Hydrogen Concentration in Big Bertha and the LXC's Contained in the Vessel, L.M. Liljegren, PNL-IX-0016, 5/16/95.

Needs to Flush IXM's to Eliminate Hydrogen Gas, L.M. Liljegren, PNL-IX-0017, 6/14/95.

Flammability Limits of Hydrogen in the IXM's, Letter from G.T. Terrones to W.C. Mills, $7 / 10 / 95$.

Oxygen Depletion in IXM, Letter from P.K. Melethil to L.M. Liljegren, 8/25/95.

Hydrogen and Oxygen Concentrations in IXC's, L.M. Liljegren, PNL-DX-0019, 9/14/95. 


\section{5ึ: Battelle \\ Pacific Northwest Division \\ P.O. Box 999 \\ Richland, Washington U.S.A. 99352 \\ Telephone (509) \\ $375-2645$}

January 31, 1995

Cherri DeFigh-Price, Manager

Restart \& Special projects

$\mathrm{K}-\mathrm{B}$ asin

Richland, WA 99352

Dear Ms. Defigh-Price:

I hereby submit a letter report entitled "Estimate of Hydrogen Concentration in KW-14" (PNL-IX-IR-0006).

The analysis in this report shows that, in a steady state, the $\mathrm{H} 2$ concentration in the void space of IXM-14 will be $1.69 \%$ or less with one $1 / 8$ " NUCFIL filter installed in the IXM. This concentration level will rise during the move if the filter is covered by a sand bag. If fifteen days are allowed for the move, the $\mathrm{H} 2$ concentration level is expected to reach $1.87 \%$ or less at the end of moving period.

It is important to note that the current analysis does not consider $\mathrm{H} 2$ transport through wet resin in the IXM - the H2 generation rate in the resin was assumed to be equal to the $\mathrm{H} 2$ supply rate in the void space. In reality, the $\mathrm{H} 2$ level in the resin can be higher than the value currently assumed and a sudden release of $\mathrm{H} 2$ bubbles is possible. So it is strongly recommended that agitations of IXM be minimized during the move.

This report was prepared for internal use only hence shouldn't be disseminated to the public. Please call me if you have questions.

Sincerely,

Inn Choi, Manager

Ion Exchange Disposal Project

IGC:kam

Enclosure

cc: William Mills / WHC Lucia Liljegren / PNL Paul Turner / PNL 
IX DISPOSTION PROJECT DOCUMENT APPROVAL FORM

Title: Estimate of Hydrogen Concentration in KW-14

Document Number:

PNL-IX-IR-0006
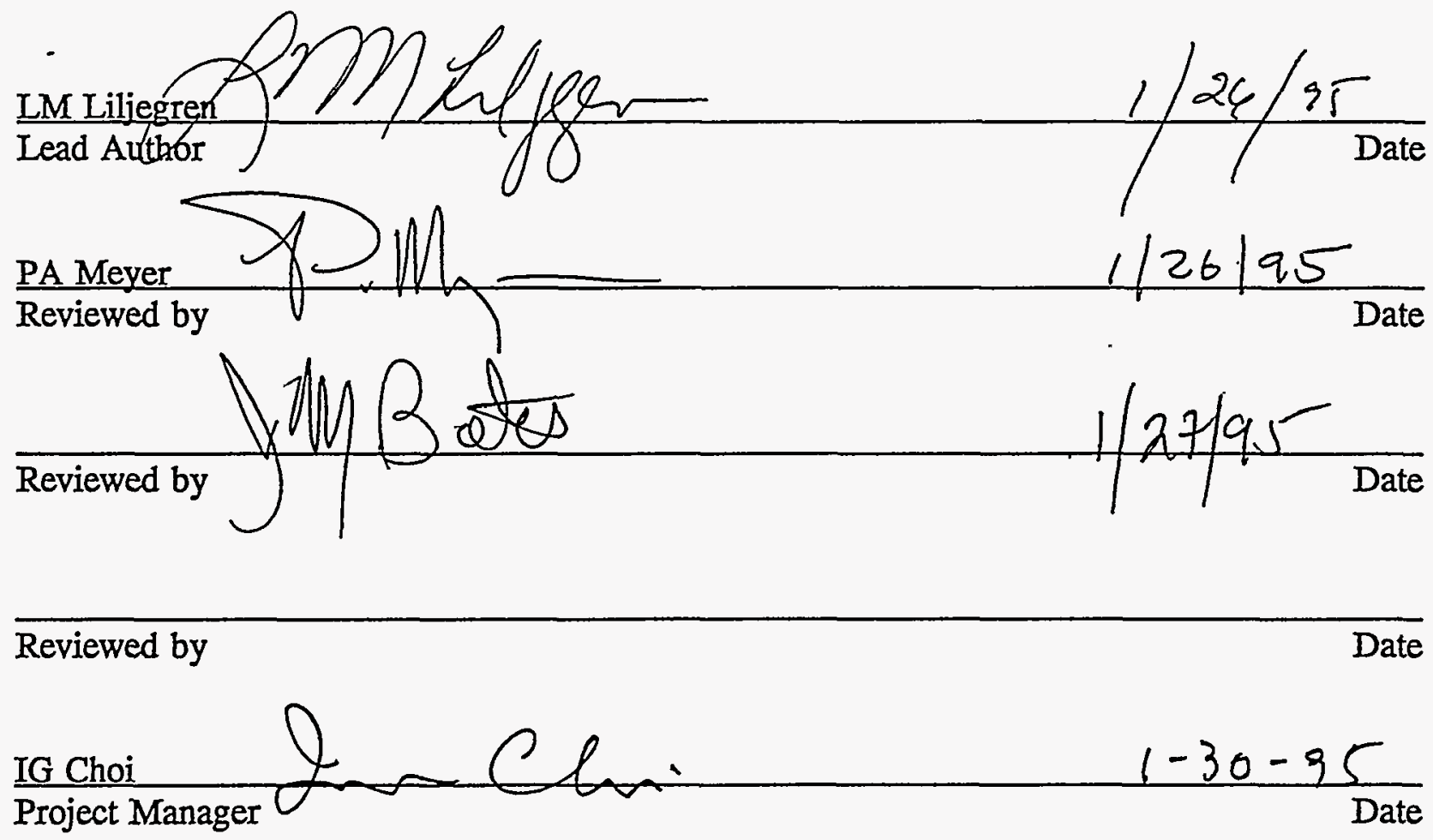


\section{Estimate of Hydrogen Concentration in KW-14}

\section{LM Liljegren}

January 26, 1995

\section{Pacific Northwest Laboratory}

Richland WA 99352 


\section{Estimate of hydrogen concentration in KW-14}

\section{LM Liljegren}

(PNL-IX-IR-0006)

\section{Introduction}

The maximum mole fraction of hydrogen in IXM KW-14 must be determined in order to plan for safe transport. This calculation is performed to determine an upper bound on the mole fraction prior to the move and during the move. The IXM has been resting as presently configured since being decommisioned. Consequently, the maximum possible mole fraction prior to the move is the steady-state concentration, or that which would be achieved if the IXM is allowed to rest with the NUCFIL filter unblocked for a long period of time after decommisioning. During the move, a sandbag will be placed over the single NUCFL filter, which is the major path for hydrogen flow. Because hydrogen is generated in the IXM, the mole fraction of hydrogen will rise during this period.

The mole fraction of hydrogen in the IXM KW-14 is estimated for two cases. These are:

- $\quad$ Case 1: IXM at steady-state.

- $\quad$ Case 2: IXM during a transient when the NUCFLL is obstructed by a sandbag.

For the purpose of estimating the Hydrogen mole fraction, I have assumed that

- Hydrogen is supplied to an open region above the resin bed at a rate equal to its generation rate.

- Hydrogen diffuses out through the one $1 / 8^{\prime \prime}$ NUCFIL filter that is installed on one of the columns of the IXM. 
- No flow is induced by changes in atmospheric pressure. This simplifies the computation, and is conservative in the sense that the actual $\mathrm{H}_{2}$ concentration are reduced by flow. The mean flow required to maintain a constant pressure is accounted for.

- The region in the open region above the resin bed mixes well. This should be reasonable based on the large diffusivity of hydrogen. However, it is not conservative.

- The hydrogen generation rate is $5.4 \times 10^{-4}$ liters/ hour at STP Hawkes (1995) 1

- No other gases are generated because of radiolisis. This will tend to over predict the hydrogen mole fraction both at steady-state and during the transient.

- Placing the sandbag over the NUCFIL filter will completely prevent both diffusion and pressure driven flow of hydrogen. This is will over predict the hydrogen concentration during transport of the IXM.

\section{Conclusion}

The conclusion of this analysis are:

1) at steady state, when the $1 / 8$ " NUCFIL filter is not blocked by a sand bag, the hydrogen mole fraction inside the open volume of air in an IXM will be $\mathrm{x}_{\mathrm{h} 2} \leq 1.69 \%$ and

2) during the move, when the NUCFIL is covered by a sand bag, the concentration will rise. After 15 days, the hydrogen mole fraction will be $\mathrm{x}_{\mathrm{h} 2} \leq 1.87 \%$

\footnotetext{
${ }^{1}$ Burke 8/24/94 cc mail (attached)
} 


\section{Limitation}

This analysis does not provide an estimate of the concentration of hydrogen in the resin bed. This prediction is deferred because adequate models for the diffusivity of hydrogen through the damp resin bed are not available. All that is known is that the hydrogen mole fraction inside the packed resin bed itself will be larger than estimated here. If the resin bed is agitated significantly during transport, the gas in the void spaces of the resin bed could mix with gas in the open volume above the resin bed. Because no adequate estimates of the hydrogen mole fraction in the resin bed are possible, it is recommended that transport be accomplished with a minimal degree of agitation.

\subsection{Lumped parameter model for hydrogen concentration.}

A conceptual sketch of an IXM is illustrated in Figure 1.1. The IXM is made up of 6 separate columns, although only two columns are illustrated in this figure. Only one column is fitted with a vent and NUCFLL filter, which allows for flow and diffusion of hydrogen. In this figure, hydrogen is supplied to a void space from the resin. Hydrogen is lost from the canister through the NUCFIL filter on the vent.

This system will be treated using a lumped parameter model; that is the free space inside the canisters will be treated as a single connected space that is vented to the atmosphere through one $1 / 8$ " NUCFL filter. Assuming that the resin in the container generates rather than consumes gas, the rate of change of the hydrogen mole fraction in the head space will obey:

$$
\begin{array}{ll}
V_{h s} \frac{d C x_{h 2}}{d t}=-x_{h 2}\left(Q_{g, 1}+Q_{g, 2}\right)-Q_{h 2, \text { nucfil }}+r_{h 2} S & \text { when } Q_{g, 2}+Q_{g 1} \geq 0 \\
V_{h s} \frac{d C x_{h 2}}{d t}=-x_{a t m}\left(Q_{g, 1}+Q_{g, 2}\right)-Q_{h 2, \text { nucfil }}+r_{h 2} S & \text { when } Q_{g, 2}+Q_{g 1}<0
\end{array}
$$


where

$\mathrm{C}=$ the molar concentration of gas in the head space of the container (mole/liter).

$\mathrm{x}_{\mathrm{atm}}=$ mole fraction of hydrogen in the atmosphere, $\left(\frac{\text { mole } \mathrm{H}_{2}}{\text { mole gas }}\right)$.

$\mathrm{x}_{\mathrm{h} 2}=$ mole fraction of hydrogen, $\left(\frac{\text { mole } \mathrm{H}_{2}}{\text { mole gas }}\right)$.

$\mathrm{Q}_{\mathrm{g}, 1}=$ pressure induced flowrate of gas out of the IXM, which is required to keep the total number of moles in the container constant, (mole/sec). This quantity is positive when gas is generated in the IXM.

$\mathrm{Qg}_{2}=$ instantaneous pressure induced flow rate of gas out of the test section due to "breathing"; on average this is zero. This quantity is set to zero in this analysis, (mole/sec).

$\mathrm{Q}_{\mathrm{h} 2 \text {,nucfil }}=$ molecular diffusion of hydrogen through the 1/8". NUCFIL filter, (mole/sec).

$\mathrm{S}=$ number of moles of gas generated per unit time. This is assumed positive, (mole/sec).

$r_{\mathrm{h} 2}=$ the fraction of the generated gas that is hydrogen, $\left(\frac{\mathrm{moleH}_{2}}{\text { mole gas }}\right)$.

$\mathrm{V}_{\mathrm{hs}}=$ the volume of the free space in the IXM, (liters).

Throughout this analysis, it will be assumed that $\mathrm{Qg}_{\mathrm{g}}=0$; this is a simplifying assumption that causes the hydrogen concentration to be overpredicted. Flow into or out of the IXM can be induced by changes in pressure outside, or changes in temperature inside the IXM. This effect has been referred to as "breathing" in Hanford documents. When this occurs, the hydrogen mole fraction will be reduced relative to cases where no such flow occurs. This can be seen by observing that $\mathrm{Qg}_{\mathrm{g}, 2} \neq 0$ never reduces, but 
Figure 1: Idealized representation of the IXM. Note, the IXM's contain 6 canisters.

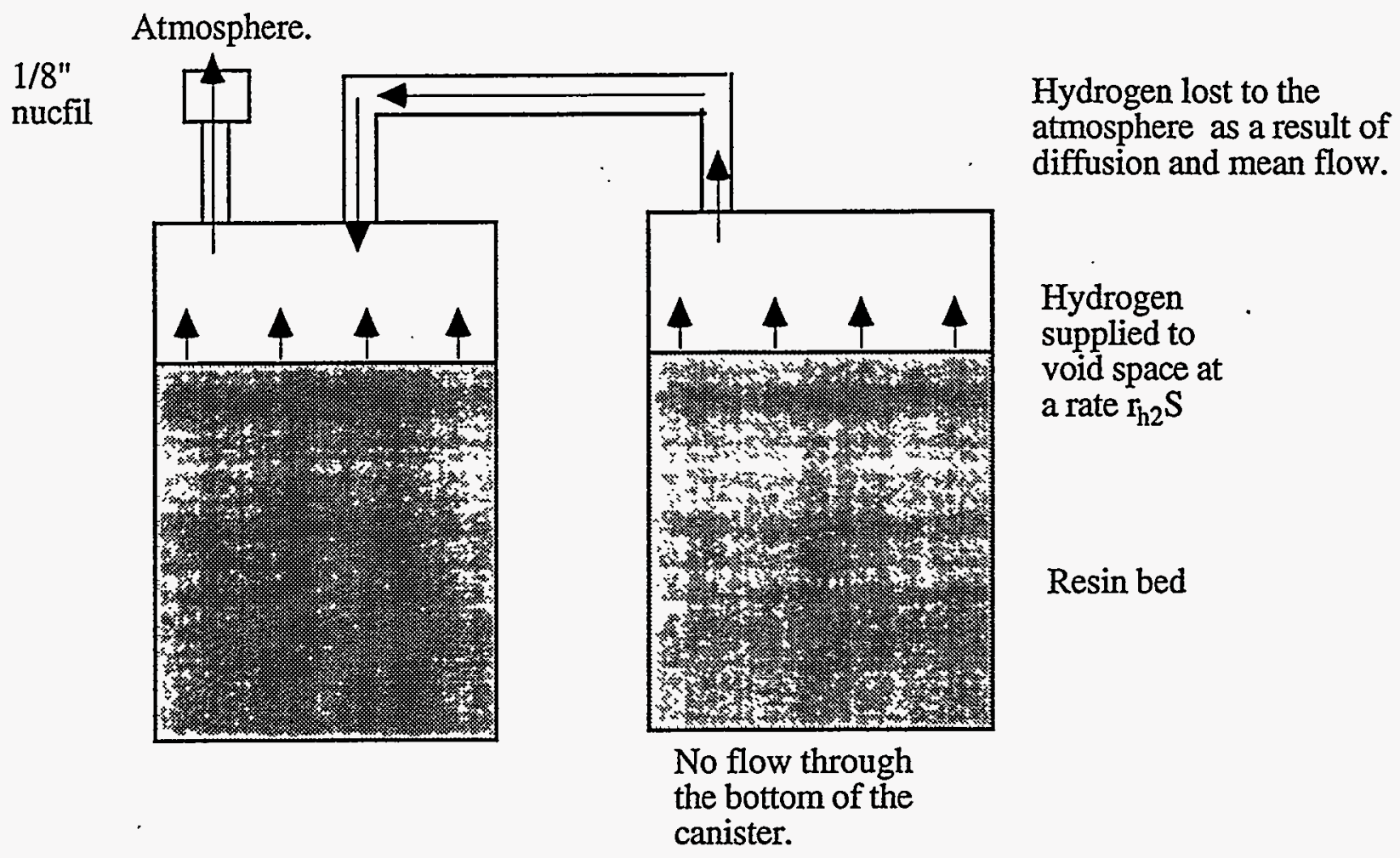

sometimes increases, the flow rate of gas leaving the IXM. To avoid the complications associated with accounting for "breathing" due to pressure changes outside the IXM, I will neglect "breathing", and set $\mathrm{Qg}, 2_{2}=0$. This is conservative in the sense the model described here will tend to over predict the hydrogen concentration in the IXM. 


\subsection{Model for Case 1: Hydrogen concentration at steady state with an unblocked NUCFIL}

To determine the steady-state value, we set $\mathrm{dx}_{\mathrm{h} 2} / \mathrm{dt}=0$ in equation (1) and solve for $\mathrm{x}_{\mathrm{h} 2}$. For this case, the permeation, or pressure induced flow rate of gas through the NUCFIL is $\mathrm{Q}_{\mathrm{g} 1}=\mathrm{S}$, of this $\mathrm{x}_{\mathrm{h} 2} \mathrm{~S}$ is hydrogen and $\left(1-\mathrm{x}_{\mathrm{h} 2}\right) \mathrm{S}$ is other gases. This flow is required to prevent the pressure of the IXM from increasing forever. Hydrogen diffuses out through the NUCFL at a rate $\mathrm{Qh}_{\mathrm{h} 2 \mathrm{nucfil}}=\mathrm{x}_{\mathrm{h} 2} \mathrm{C} / \mathrm{R}_{\text {tot }}$ where $\mathrm{R}_{\mathrm{tot}}$ is the effective resistance to diffusion of the NUCFL pipe line combination. The magnitude of $R_{\text {tot }}$ is calculated in Section 3.1. For this entire analysis, it is assumed that $\mathrm{Qg}_{\mathrm{g} 2}=0$. Substituting into and dividing by the mole concentration of gas at STP, CSTP, (1) becomes:

$0=\left(\mathrm{r}_{\mathrm{h} 2}-\mathrm{x}_{\mathrm{h} 2}\right) \frac{\mathrm{S}}{\mathrm{C}_{\mathrm{stp}}}-\mathrm{x}_{\mathrm{h} 2} \frac{\mathrm{C}}{\mathrm{C}_{\mathrm{stp}}} \frac{1}{\mathrm{R}_{\mathrm{tot}}}$

This may be solved for $\mathrm{x}_{\mathrm{h} 2}$

$$
x_{h 2}=r_{h 2} \frac{1}{\left[1+\left(R_{\text {tot }} \frac{C_{\text {stp }}}{C} \frac{S}{C_{\text {Stp }}}\right)^{-1}\right]}
$$

Hawkes (1995) indicates that $\mathrm{r}_{\mathrm{h} 2}$ is approximately equal to 1 . Because the maximum value of $x_{\mathrm{h} 2}$ occurs when $\mathrm{r}_{\mathrm{h} 2}=1$, we will use this value for further analysis. Because the IXM is at a slightly greater pressure than the air outside the IXM, the mole concentration inside the IXM will exceed that outside. It is conservative to use $C_{S T P} / C=T_{a t m} / T_{S T P}$. The temperature outside the IXM is approximately $25 \mathrm{C}$. We will evaluate (3) using $\mathrm{C}_{\mathrm{STP}} / \mathrm{C}=(273.15+25) / 273.15$ resulting in

$$
x_{\mathrm{h} 2}=\frac{1}{\left[1+\left(R_{\text {tot }} \frac{C_{\text {stp }}}{C} \frac{S}{C_{\text {stp }}}\right)^{-1}\right]}
$$


For LXM KW-14, S/C STP $=5.4 \times 10^{-4}$ liters/hour (Hawkes, 1995) and is provided at STP.

The resistance to diffusion through the NUCFIL is estimated to be $1.05 \times 10^{5}$ sec/liter;

see Section 3.1. This results in a hydrogen estimate of $\mathrm{x}_{\mathrm{h} 2}=\left[1+\left(1.05 \times 10^{5} \mathrm{~s} / \mathrm{liter}\right.\right.$ $\left.\left(\frac{273.15+25}{273.15}\right) 5.4 \times 10^{-4} \mathrm{liters} / \mathrm{hr} 1 \mathrm{hr} / 3600 \mathrm{~s}\right)^{-1} \mathrm{~J}^{-1}=1.69 \%$ at steady state.

\subsection{Model for Case 2: Hydrogen concentration during the transient when the NUCFIL is blocked.}

During the transient, the NUCFL will be blocked by a sandbag. For this case, the pressure induced flow out of the NUCFIL is zero; $\mathrm{Q}_{\mathrm{g} 1}=\mathrm{Q}_{\mathrm{g} 2}=0$. Equation (1) becomes

$\mathrm{V}_{\mathrm{hs}} \frac{\mathrm{dCx}_{\mathrm{h} 2}}{\mathrm{dt}}=\mathrm{r}_{\mathrm{h} 2} \mathrm{~S}$

Conservation of mass also requires the total concentration in the open volume of the IXM, C, to obey

$$
\frac{\mathrm{dC}}{\mathrm{dt}}=\frac{\mathrm{S}}{\mathrm{V}_{\mathrm{hs}}}
$$

The solutions for $\mathrm{C}$ and the product $\mathrm{Cx}_{\mathrm{h} 2}$ are

$$
\begin{aligned}
& C(t)=C(0)+\frac{S}{V_{h s}} t \\
& C x_{h 2}(t)=C x_{h 2}(0)+\frac{h_{h 2} S}{V_{h s}} t
\end{aligned}
$$

Assume that 1) the mole concentration of gases is at standard temperature and pressure at $t=0$, that is $C(0)=C_{\text {stp }}$ and 2)the mole fraction of hydrogen at $t=0$ is the steady state 
value obtained in section $\mathrm{x}_{\mathrm{h} 2}=1.69 \%$. For this set of initial conditions, the result of $\mathrm{x}_{\mathrm{h} 2}(\mathrm{t})$ becomes

$\mathrm{x}_{\mathrm{h} 2}(\mathrm{t})=\frac{\mathrm{Cx}_{\mathrm{h} 2}(0)+\frac{\mathrm{Th}_{2} \mathrm{~S}}{\mathrm{~V}_{\mathrm{hs}}} \mathrm{t}}{\mathrm{C}(0)+\frac{\mathrm{S}}{\mathrm{V}_{\mathrm{hs}}} \mathrm{t}}=\frac{0.0169+\frac{\mathrm{T}_{\mathrm{h} 2} \mathrm{~S}}{\mathrm{C}_{\mathrm{STP}} V_{\mathrm{hs}}} \frac{\mathrm{C}_{\mathrm{STP}}}{\mathrm{C}} \mathrm{t}}{1+\frac{\mathrm{S}}{\mathrm{C}_{\mathrm{STP}} \mathrm{V}_{\mathrm{hs}}} \frac{\mathrm{C}_{\mathrm{STP}}}{\mathrm{C}} \mathrm{t}}$

Note that according to this solution at $\mathrm{t} \rightarrow \infty, \mathrm{x}_{\mathrm{h} 2} \rightarrow \mathrm{r}_{\mathrm{h} 2}$, and $\mathrm{C} \rightarrow \infty$. Before this occurs, gas will begin to flow out of the NUCFIL, which will prevent hydrogen from accumulating as quickly as predicted by (9) and prevent the gas concentration from rising as high as predicted by (8). Consequently, (9) over predicts the hydrogen accumulation, but is adequate at small times. The model may be further refined if warranted.

When $\mathrm{r}_{\mathrm{h} 2}=1$ the rate of accumulation is

$\mathrm{x}_{\mathrm{h} 2}(\mathrm{t})=\frac{\mathrm{Cx}_{\mathrm{h} 2}(0)+\frac{\mathrm{S}}{\mathrm{V}_{\mathrm{hs}}} \mathrm{t}}{\mathrm{C}(0)+\frac{\mathrm{S}}{\mathrm{V}_{\mathrm{hs}}} \mathrm{t}}=\frac{0.0169+\frac{\mathrm{S}}{\mathrm{CSTP}_{\mathrm{hs}}} \frac{\mathrm{CSTP}_{\mathrm{STP}}}{\mathrm{C}} \mathrm{t}}{1+\frac{\mathrm{S}}{\mathrm{CSTPV}_{\mathrm{hs}}} \frac{\mathrm{CSTP}_{\mathrm{STP}}}{\mathrm{C}} \mathrm{t}}$

If we assume that the IXM was at steady-state prior to placing the sandbag, then $\mathrm{x}_{\mathrm{h} 2}=$ $1.69 \%$ as predicted in section 1.1. The hydrogen generation rate provided by Hawkes (1995) is $\mathrm{S} / \mathrm{C}_{\mathrm{stp}}=5.4 \times 10^{-4}$ liters/hour.

The exact volume of the IXM is not easily obtainable. However, each of the six columns in the IXM can be approximated as a $16^{\prime \prime}$ diameter $\times 42$ " tall cylinder. Because the IXM corners are rounded, assuming a perfect cylinder would slightly overestimate the volume of the IXM, causing a small underestimation in the hydrogen mole fraction. Based on IXM detail drawing H-1-46279, the depth of radius of curvature on both the top and 
bottom of the IXM is less than 3.5" and subtracting 7" from the total height of the IXM will provide the lower bound on the internal volume of each column. The IXM columns will be assumed to be a 16" diameter by (42"-7") tall cylinder. The volume of a $16^{\prime \prime} \mathrm{x}$ $35^{\prime \prime}$ cylinder is $1.15 \times 10^{-1} \mathrm{~m}^{3}$. Resin occupies $3.5 \mathrm{ft}^{3}$ of each IXM column (Marusich 1994); the open volume in one column is the difference between the volume of a 16" diameter, $35^{\prime \prime}$ tall cylinder and the $3.5 \mathrm{ft}^{3}$ occupied by the resin or $1.62 \times 10^{-2} \mathrm{~m}^{3}$. The open volume for all 6 cylinders is $9.73 \times 10^{-2} \mathrm{~m}^{3}$.

Based on these values, the hydrogen mole fraction when the sandbag is first placed over the NUCFL, and 5 and 10 days later are provided table 1 . The approximate increase in the concentration of the gas in the IXM normalised by the concentration at standard temperature and pressure is also provided.

Table 1. Hydrogen concentration variation with time after the sandbag is placed over the NUCFIL.

\begin{tabular}{|l|l|l|}
\hline Mole Fraction $\mathrm{x}_{\mathrm{h} 2}$ & $\mathrm{C} / \mathrm{CSTP}_{\mathrm{ST}}-1$ & Time \\
\hline $1.69 \%$ & 0 & 0 \\
\hline $1.75 \%$ & $6.7 \times 10^{-4}$ & 5 days \\
\hline $1.81 \%$ & $1.3 \times 10^{-3}$ & 10 days \\
\hline $1.87 \%$ & $2.0 \times 10^{-3}$ & 15 days \\
\hline
\end{tabular}

The model predicts that the mole fraction of hydrogen in the open volume above the resin bed will remain below $1.87 \%$ for 15 days after placement of the sandbag. Both the models for the steady state value and the model predicting the increase in hydrogen during the transient over-predict the hydrogen concentration somewhat. Better models could reduce the degree of overprediction somewhat. However, because the predicted 
values are sufficiently low to allow for transport of the IXM, no further refinement of the model is warranted.

\subsection{Effective resistance of the NUCFIL filter and vent.}

One column inside an IXM KW-14 is equipped with a NUCFL filter that allows gas to flow into the atmosphere. The NUCFIL filter is mounted at the end of a long run of vent piping. Each of the six columns inside the IXM are inter-connected by series of pipes. I will treat IXM KW-14 as a single column which is separated from the NUCFIL by a length of pipe with a resistance equal to maximum resistance between the any of the individual columns and the NUCFL; see Fig. 2 for a conceptual sketch of the resistance. The resistance of this system is modeled as equal to the sum of the resistance of the NUCFLL itself and the resistance of all vent piping. This model will over predict the hydrogen concentration at steady state for all six columns from the NUCFIL. 
Figure 2: Simplified model of the effective resistance to diffusion of hydrogen from an IXM.
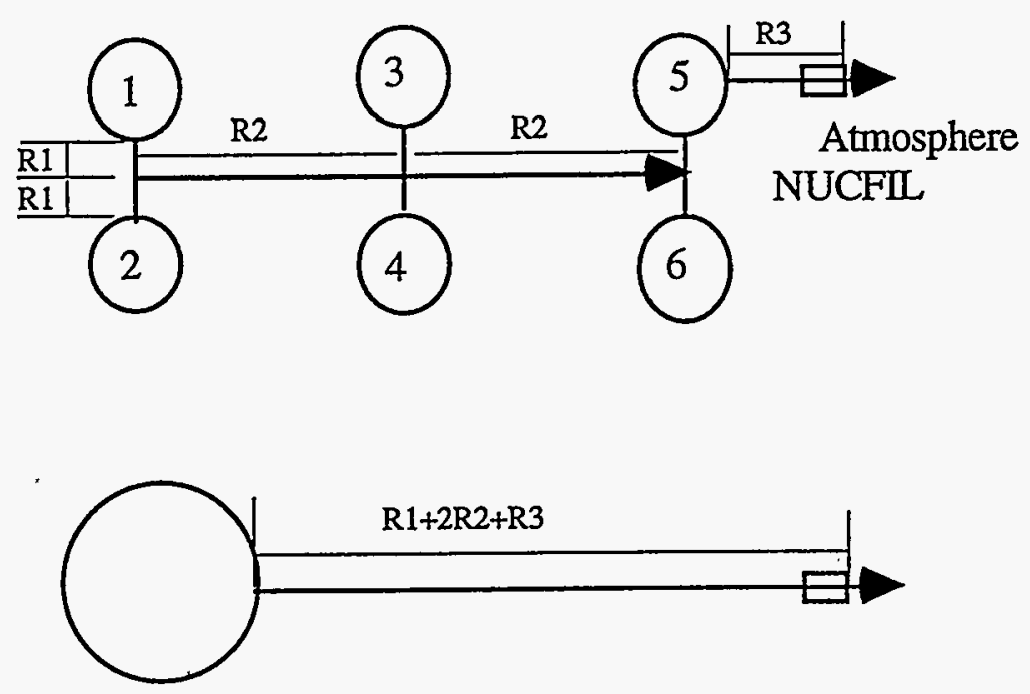

Actual system vs. Simplified model with the resistance equal to than from column 1 to the atmosphere.

Assuming constant concentration of gas, C, throughout each tank, the diffusion of hydrogen relative to mean flow may be modeled as

$\frac{\mathrm{Q}_{\mathrm{h} 2 \text { nucfil }}}{\mathrm{C}_{\mathrm{stp}}}=\frac{\mathrm{C}\left(\mathrm{x}_{\mathrm{h} 2, \mathrm{~atm}}-\mathrm{x}_{\mathrm{h} 2)}\right.}{\mathrm{C}_{\mathrm{stp}} \mathrm{R}_{\mathrm{tot}}}$

where $\mathrm{R}_{\text {tot }}$ is the resistance of the NUCFIL filter and vent combination.

We will assume that the concentration of hydrogen in the atmosphere is 0 . So, the rate at which hydrogen that diffuses through the NUCFL is

$\frac{\mathrm{Q}_{\mathrm{h} 2 \text { nucfil }}}{\mathrm{C}_{\mathrm{stp}}}=\frac{\mathrm{C} \mathrm{x}_{\mathrm{h} 2}}{\mathrm{C}_{\mathrm{stp}} \mathrm{R}_{\mathrm{tot}}}$ 
I will use a model that is very similar to that described in Marusich 1994. This assumes equal effective diffusivities for hydrogen through the gas filled region and the NUCFIL filter materiais. The assumed value for diffusivity of Hydrogen is $0.41 \mathrm{~cm}^{2} / \mathrm{s}$, as in Marusich (1994). This value is conservative relative to a diffusivity of hydrogen through air of $2.75 \mathrm{~cm}^{2} / \mathrm{s}$ at $25^{\circ} \mathrm{C}$ listed in the $\mathrm{CRC}$ handbook ${ }^{2}$; using a low value of diffusivity will over-predict the resistance of the Nucfil filter- vent system, and over predict the hydrogen concentration in the IXM.

The resistance of a 1/8 inch NUCFIL is modeled in Marusich. The dimensions of this filter are given in Marusich 1994 on pages 14-15. The critical resistance is due to the $1 / 8^{\prime \prime}$ hole in the plug, and the $1 / 8^{\prime \prime}$ hole in the connecting pipe to the filter. The crosssectional areas for each of these is $0.079 \mathrm{~cm}^{2}$, which corresponds to a $1 / 8$ " diameter opening.

The resistance of each segment is

$\mathrm{R}=\frac{\mathrm{L}}{\text { Area }} \frac{1}{\mathrm{D}_{\mathrm{h} 2 \text {-air }}}$

Where $L$ is the length of a segment and $A$ is its area. Resistances of items in series is the sum of all resistances. The resistance of the NUCFIL filter is then

$$
\begin{aligned}
\mathrm{R}_{\text {nucfil, } 1 / 8} & =\left\{\left[\frac{0.25+0.25+0.48}{0.079}+\frac{0.75+1.91}{2.83}\right] \frac{1}{\mathrm{~cm}}\left[\frac{1}{0.41} \frac{\mathrm{s}}{\mathrm{cm}^{2}}\right]\right. \\
& =32.5 \mathrm{~s}-\mathrm{cm}^{-3}
\end{aligned}
$$




\subsection{Model the resistance due to the vent pipe}

The vent pipe consists of a 20 inch long 1/2" schedule 40 pipe (Marusich 1994). The resistance of the pipe is

$$
\begin{aligned}
\mathrm{R}_{\text {vent1 }} & =\frac{(4)(20)}{\pi 0.622} \frac{1}{\text { in }} \frac{\text { lin }}{2.54 \mathrm{~cm}}\left[\frac{1}{0.41} \frac{\mathrm{s}}{\mathrm{cm}^{2}}\right] \\
& =25.90 \frac{1}{\mathrm{~cm}}\left[\frac{1}{0.41} \frac{\mathrm{s}}{\mathrm{cm}^{2}}\right]=63.2 \mathrm{~s}-\mathrm{cm}^{-3}
\end{aligned}
$$

Based on IXM model detail H-1-46279, the longest run of pipe including internal stand pipe between the inlet of the pipe attached to the NUCFL and an individual column is the sum of $(2)\left(16^{\prime \prime}\right)+2 \times 8^{\prime \prime}+2 \times 9.5^{\prime \prime}=67^{\prime \prime}$. For a first estimate, I will assume that the IXM can be treated as one canister with an open volume that is separated from the inlet to the pipe on the NUCFLL by a $67^{\prime \prime}$ long pipe. The diameter of the connecting pipe is $3^{\prime \prime}$. A better estimate could be obtained by modeling each canister individually, and tying into the piping network. Because 1)the level of hydrogen was found to be below the lower flammability limit even after the NUCFIL was covered with a sandbag for 15 days and 2) the resistance due to the 67 " pipe is much less than the resistance due to the NUCFIL and vent pipe, I judge that the additional level of detail is not warranted. Treating the IXM as one canister with only one pipe will tend to over predict the resistance to hydrogen transport and over predict the hydrogen concentration, which is conservative.

The resistance of this piping is

$$
\mathrm{R}_{\text {pipe }}=\frac{(4)(67 \mathrm{in})}{\pi 3^{2} \text { in } 2} \frac{1 \text { in }}{2.54 \mathrm{~cm}}\left[\frac{1}{0.41} \frac{\mathrm{s}}{\mathrm{cm}^{2}}\right]=9.10 \mathrm{~s}-\mathrm{cm}^{-3}
$$


The resistance of the NUCFL/vent combination is

$R_{\text {tot }}=\left[R_{\text {nucfil }}+R_{\text {vent }}+R_{\text {pipe }}\right]=[32.5+63.2+9.10] \mathrm{s}-\mathrm{cm}^{-3}=1.05 \times 10^{2} \mathrm{~s}^{-\mathrm{cm}^{-3}}(17)$

These resistances are comparable in magnitude to those in Marusich ${ }^{3}$. It is convenient to express this in terms of $\mathrm{s}-$ liters $^{-1}$.

$\mathrm{R}_{\mathrm{tot}}=1.06 \times 10^{2} \mathrm{~s}-\mathrm{cm}^{-3} \frac{1000 \mathrm{~cm}^{3}}{1 \mathrm{liter}}=1.05 \times 10^{5} \mathrm{~s}^{-\mathrm{liter}^{-1}}$

\section{References}

Marusich, R.M. 6/21/94 Hydrogen Production in the K-Basin Ion Exchange Columns, Modules and Cartridge Filters, and the Significance of that Production. WHC draft memo.

Hawkes, E. 1995 Gas Generation Rate in IXM KW-14 January 16, 1995 memo, for information only.

${ }^{3}$ Marusich 6/15/94, see page 36. 
May 16, 1995

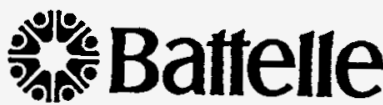

Pacific Northwest Division P.O. Box 999

Richland, Washington U.S.A. 99352

Telephone (509)

$375-2353$

Cherri DeFigh-Price, Manager

Restart \& Special Projects

K-Basin

Richland, WA 99352

Dear Ms. Defigh-Price:

I am submitting a document entitled "Estimate of Hydrogen Concentration in Big Bertha and the IXC's contained in the Vesse]" by LM Liljegren.

Based on the analysis, the hydrogen mole fraction anywhere in Big Bertha is less than $0.4 \%$ This is below the lower flammability of hydrogen in air of $4 \%$ by volume.

Please note the single important limitation of the analysis, which is that the resin is assumed to be well drained. This assumption appears to be valid for a resin that has been allowed to drain for nearly 4 years.

If you have future questions, please call Lucia Liljegren at 375-2353.

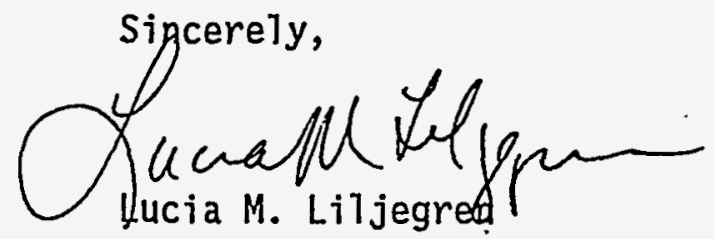

$\mathrm{LML} / \mathrm{kr}$

Enclosure

cc: WiTliam Mills/WHC

Paul Turner/PNL

Jim Bates/PNL_ 


\section{DISPOSITION PROJECT}

DOCUMENT APPROVAL FORM .

Title: $\quad$ Estimate of Hydrogen Concentration in Big Bertha and the IXC's Contained in the Vessel

Document Number:

PNL-IX-IR-0016

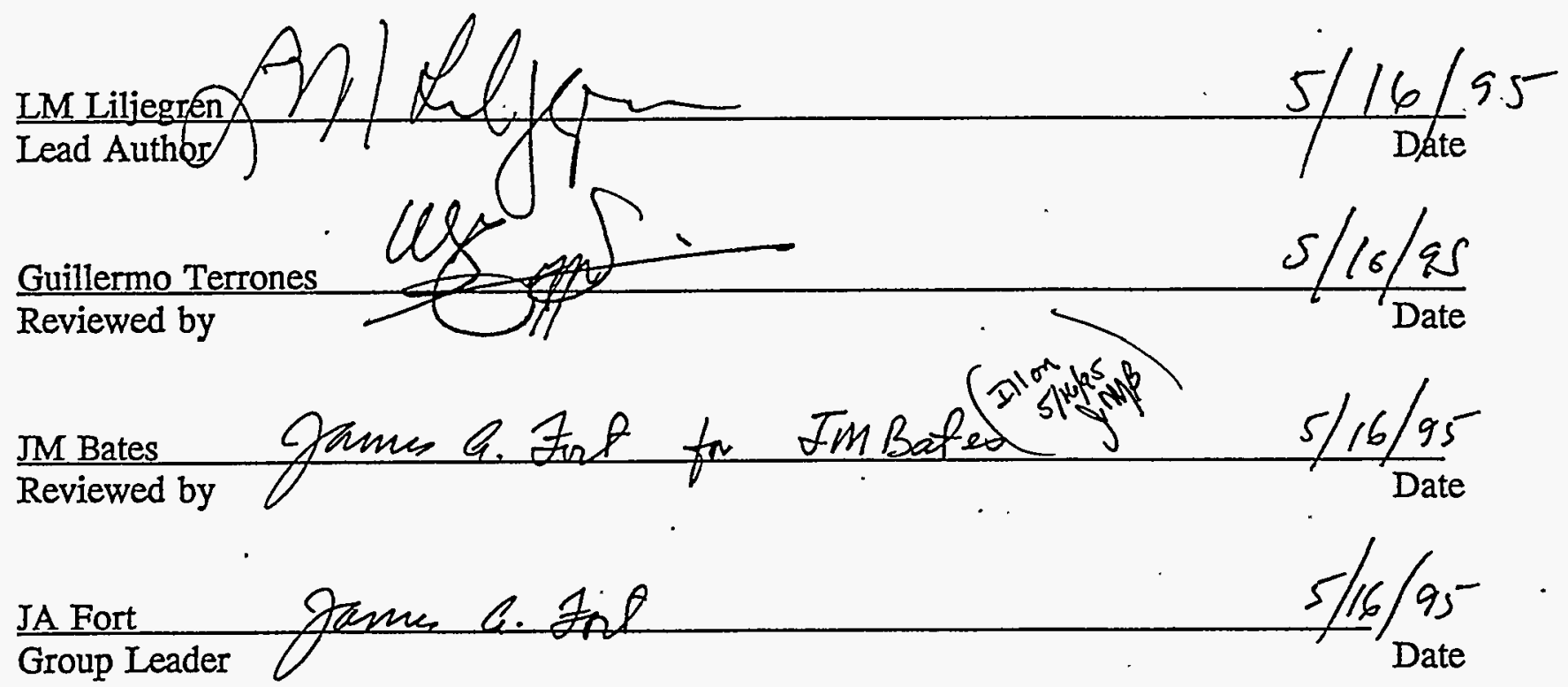


PNL-IX-IR-0016

Estimate of Hydrogen Concentration in Big Bertha and the IXC's Contained in the Vessel

L. M. Liljegren

May 15, 1995

Pacific Northwest Laboratory

Richland WA 99352 


\section{Estimate of hydrogen concentration in Big Bertha and the IXC's contained}

\section{in the vessel}

LM Liljegren

(PNL-IX-IR-0016)

\section{Summary}

The maximum mole fraction of hydrogen in Big Bertha must be determined to plan for safe transport. This calculation is performed to determine an upper bound on the hydrogen mole fraction at quasi-steady state. The maximum possible mole fraction before the move is the steady-state concentration, or that which would be achieved if the cask is . allowed to rest undisturbed for a long time after decommisioning.

The conclusions of this analysis are:

- The maximum possible hydrogen concentration in the open volume inside Big . Bertha but outside the individual IXC's is $<0.1 \%$.

- The maximum possible hydrogen concentration in an individual IXC occurs at the bottom of an IXC and is $<0.4 \%$.

Both values are below the LFL of $4 \%$ for hydrogen in air.

The mole fraction in Big Bertha but outside the IXC's contained in Big Bertha was predicted using a "breathing" model. This model assumes that the only mechanism for hydrogen loss is transport due to flow induced by barometric pressure changes. The concentration inside the individual IXC's is predicted using a "diffusion" model. This assumes that the only mechanism for hydrogen loss is due to molecular diffusion. Three 
mechanisms always exist simultaneously, neglecting a mechanism tends to over predict the hydrogen level.

\section{Limitation}

A number of assumptions were made during this analysis. With one exception all were conservative in the sense that they over predict the hydrogen concentration. The sole exception is that it was assumed that the beads in the resin bed contain water but the large pores between the beads are not filled with water. Most specifically, it is assumed that water does not exist in continuous horizontal sheets that block vertical flow of hydrogen.

This assumption appears plausible because 1) the resin bed sits on an open mesh and has been allowed to drain nearly 5 years, 2) the resin bed is at an elevated temperature that would tend to drive off water and 3) if horizontal sheets of water exist, the hydrogen would exceed the solubility limit in water. Bubbles would come out of solution and break up the continuous sheets of water. Based on these arguments, it seems highly implausible that continuous regions of saturated resin exist in the IXC.

The hydrogen concentration in the presence of saturated resin has not been estimated. This is primarily due to the extreme difficulty of performing a realistic analysis. All that is known is that diffusivity of hydrogen through water is extremely low, and it has not been proven that the hydrogen mole fraction is less than the LFL if the resin bed is saturated. 


\subsection{Description of Big Bertha}

Big Bertha is designed to be a transportation vessel for IXC. Figure 1 is a conceptual illustration that is adequate from the point of view of transport modeling. Big Bertha is a large container with an opening to the atmosphere; the opening is large enough to allow gas to flow. Six IXC's are contained in Big Bertha. Each IXC is fitted with a NUCFL filter, which permits some gas transport. The IXC's are also wrapped in plastic bags. If the bags have not punctured, gas transport between the IXC's and Big Bertha occurs by diffusion only. Larger concentrations of hydrogen are predicted by assuming that all plastic bags are intact. This assumption was made here.

Note that no dimensions are provided on Figure 1. Although unusual for transport calculations, few dimensions of Big Bertha affect strongly affect the predicted values for hydrogen concentration in this particular analysis. The only dimensions that affect the results strongly are the upper and lower bounds for the volume of gas that participates in "Breathing". The major source of error in determining the volume is not due to the . physical dimensions of Big Bertha. It arises from not knowing how much the pressure inside the IXC's changes during breathing. If flow through the NUCFIL is very rapid, then the gas exits the IXC's, and the effective volume during breathing is the entire interior volume of Big Bertha including gas in the IXC's. If the NUCFUL inhibits flow, then the volume of air inside IXC's must be excluded from the calculation.

Because the major source of error is not due to the actual engineered dimension but due to detailed flow considerations, approximate dimensions based on the assumption that all internal and external geometries are perfect cylinders are used. Either maximum or minimum dimensions are used, depending on which dimensions provide the more 
conservative estimate during a particular prediction. Detailed drawings are describing geometric features are available. However, only a few features are important for the purposes of modeling. Based on the lid for Big Bertha, the internal diameter is less than $66.125^{\prime \prime}$ and the external diameter of IXC's is less than $191 / 8^{\prime \prime}$. The internal height of Big Bertha is 75", and the IXC's that fit inside Big Bertha are also less than 75" tall. Using more precise values of this dimension affect the maximum predicted concentration in the worst case IXC by $<20 \%$ of the total predicted value. That is, the final predicted value may be as low as $0.32 \%$ rather than the $0.4 \%$ described in the summary.

Gases are generated or consumed in the resin contained in each IXC. Estimates of the hydrogen generation rates are provided by Hawkes (1995). For the purpose of modeling, we will use two generation rates. First, the total hydrogen generation rate in all six IXC's is $8.93 \times 10^{-4}$ liters @STP/hr. Second, the maximum hydrogen generation rate in an individual IXC is $2 . \dot{4} \times 10^{-4}$ liters @ STP / hr which occurs in IXC KW 60.

Gas transport occurs as follows: Hydrogen is generated in the resin. Hydrogen travels by diffusion and permeation from the resin to the void space above the resin, and then through the NUCFIL to the region inside the plastic bag. The Hydrogen then permeates through the bag into the open volume in Big Bertha, and finally flows through an opening in Big Bertha exhausting to the atmosphere, where it can diffuse rapidly. In this scenario, the maximum hydrogen concentration exists at the bottom of the resin bed, and decreases to zero in the atmosphere.

Final results of this analysis will provide upper bounds for the hydrogen concentration in the open volume in Big Bertha, and the bottom open volume in the IXC. 


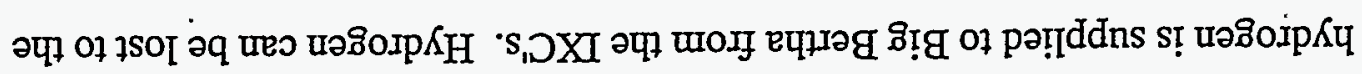

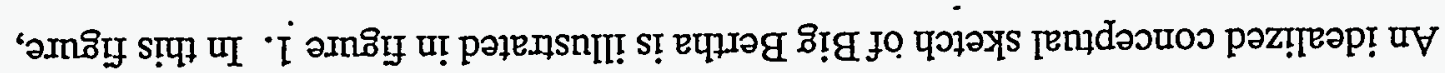

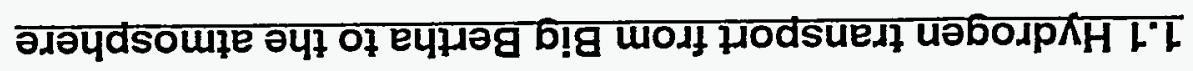

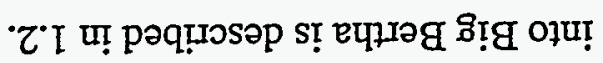

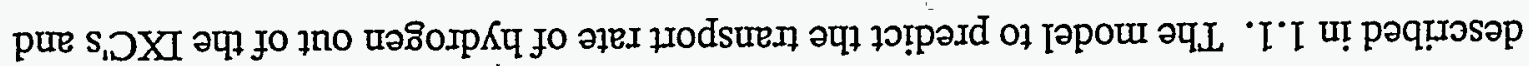

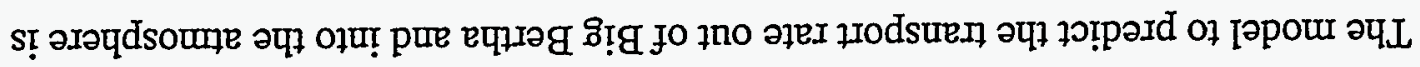

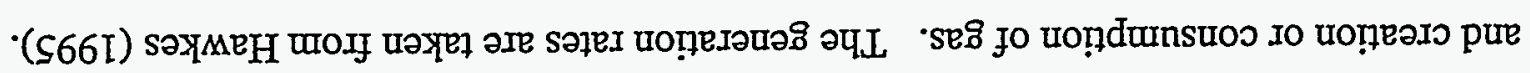

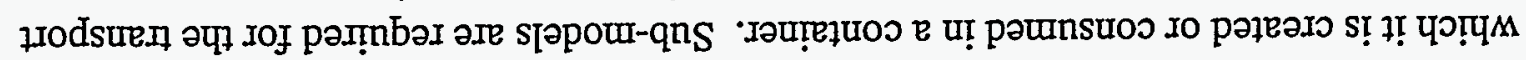

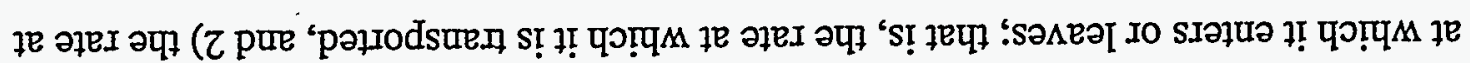

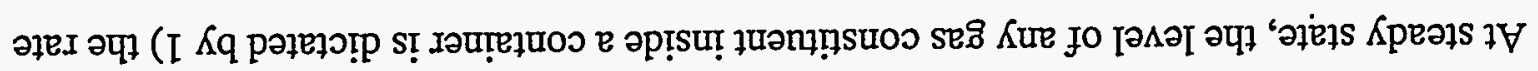

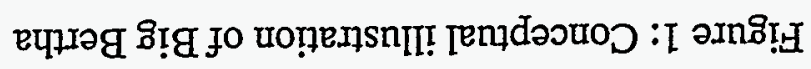

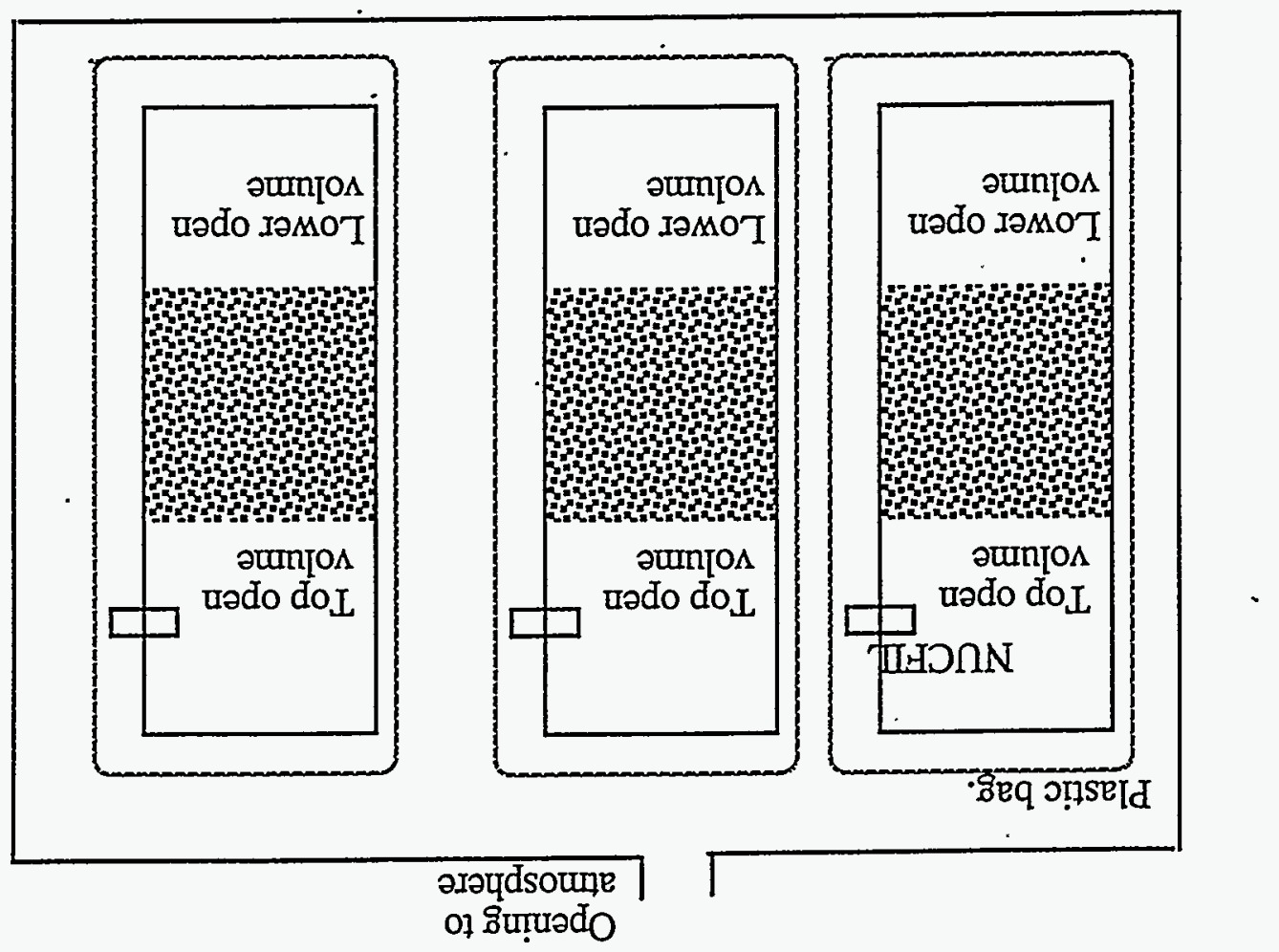


atmosphere by one of three mechanisms 1) "breathing", by which I mean hydrogen is carried out of the cask when hydrogen contaminated air flows out as a result of a drop in the atmospheric pressure and is replaced by pure air when the barometric pressure rises, 2) molecular diffusion, and 3) mean permeation, by which I mean hydrogen is carried out because there is an average flow rate out of a container to ensure that the pressure in the contäiner does not increase forever.

The most accurate estimates of the concentration require models for all three transport mechanisms. However, in some cases one predominates, and accounting for the dominant mechanism provides adequate predictions. The effect of neglecting a mechanism is to over predict the concentration of gases generated in the container. So, for example if hydrogen is generated in Big Bertha, a model that accounts for only one of the three mechanisms will over predict the hydrogen level.

For the purposes of predicting the concentration in the void space inside Big Bertha but outside the IXC's, only breathing will be considered. This is done for four reasons 1 ) information to develop a breathing model exists 2) sufficient information to develop an accurate diffusion model does not exist 3) the breathing model indicates that the upper bound on the hydrogen concentration in the open gas volume in Big Bertha is 0.1\% which is well below $4 \%$, the LFL for hydrogen and 4) the uncertainties associated with predicting the level in the individual IXC's in not reduced significantly by developing a more complicated model for Big Bertha.

The model to predict the hydrogen concentration will now be described.

At any time, the number of moles of gas /unit volume of inside Big Bertha varies as 
$\mathcal{v} \frac{d c}{d t}+\dot{N}=S_{H_{2}}+S_{O_{2}}$

where $c$ is the number of moles per unit volume in the open space in Big Bertha, $\chi_{\mathrm{H}_{2}}$ is the volume fraction of a Hydrogen, $\chi_{\mathrm{O}_{2}}$ is the volume fraction of Oxygen, $S_{\mathrm{H}_{2}}$ in the hydrogen generation rate, $S_{\mathrm{O}_{2}}$ is the rate at which Oxygen is generated, and $\dot{N}$ is the number of moles of gas leaving per unit time, that is the flow rate of hydrogen out of Bertha. It is anticipated that the generation rate of hydrogen is positive, and the generation rate of Oxygen is depleted, which corresponds to a negative value for $S_{\mathrm{O}_{2}}$.

This equation assumes that the gas source to Bertha is constant and unaffected by breathing in the IXC's. This is a reasonable assumption, because the major mechanism for flow from the IXC's to the void space in Big Bertha is molecular diffusion, which does not vary significantly with barometric pressure variations.

Net flow from Big Bertha to the atmosphere occurs as a result of pressure differences. Generally, the volumetric flow rate can be written in terms of pressure difference between two points and a flow resistance. When temperature is constant along the flow path, the ideal gas law can be used to convert the pressure into a moler concentration $c_{a r m}$, and the volumetric flow rate $Q$ can be converted into a moler flow rate $\dot{N}$. This conversion is described in Liljegren (1995). The consequence is that $\dot{N}$ may be approximated using

$$
\dot{N}=\frac{c-c_{a m m}}{\alpha}
$$

where $c_{a t m}$ is the number of moles of gas per unit volume in the atmosphere and $\alpha$ is a flow resistance with dimensions time/volume. The exact relation includes a term that describes the effect of temperature variations along the flow path; this effect is small. 
The equation describing the material balance for Hydrogen or Oxygen differs when gas enters or leaves Big Bertha. An "out breath" is defined as a period when $\dot{N}$ is positive, that is the net flow of gas is from Big Bertha to the atmosphere. An "in breath" is a period of time when $\dot{N}$ is negative. The equations differ because the number of moles of hydrogen leaving during an out breath is the product of the mole fraction of hydrogen inside Big Bertha, and the molar flow rate. During an in breath, the transport in is the product of the concentration outside Big Bertha and the molar flow rate. So the transport equations for Hydrogen and Oxygen during and out breath are:

$$
\begin{gathered}
\mathcal{V}\left(c \frac{d \chi_{H_{2}}}{d t}+\chi_{H_{2}} \frac{d c}{d t}\right)+\chi_{H_{2}} \dot{N}=S_{H_{2}} \\
\mathcal{V}\left(c \frac{d \chi_{O_{2}}}{d t}+\chi_{O_{2}} \frac{d c}{d t}\right)+\chi_{O_{2}} \dot{N}=S_{O_{2}}
\end{gathered}
$$

where $\chi_{\mathrm{H}_{2}}$ is the volume fraction of a Hydrogen in the big Bertha, $\chi_{\mathrm{O}_{2}}$ is the volume fraction of Oxygen, $S_{\mathrm{H}_{2}}$ in the hydrogen generation rate from all six canisters, $S_{\mathrm{O}_{2}}$ is the rate at which Oxygen is generated in all six canisters, and $\dot{N}$ is the number of moles of gas leaving per unit time, that is the flow rate of hydrogen out of Bertha. It is anticipated that the generation rate of hydrogen is positive, and the generation rate of Oxygen is depleted, which corresponds to a negative value for $S_{\mathrm{O}_{2}}$.

$$
\begin{aligned}
& \nu\left(c \frac{d \chi_{\mathrm{H}_{2}}}{d t}+\chi_{\mathrm{H}_{2}} \frac{d c}{d t}\right)+\chi_{\mathrm{H}_{2} \mathrm{~atm}} \dot{N}=S_{\mathrm{H}_{2}} \\
& \nu\left(c \frac{d \chi_{\mathrm{O}_{2}}}{d t}+\chi_{\mathrm{O}_{2}} \frac{d c}{d t}\right)+\chi_{\mathrm{O}_{2} \mathrm{~atm}} \dot{N}=S_{\mathrm{O}_{2}}
\end{aligned}
$$


A detailed solution of these equations assuming a sinusoidal variation for the barometric pressure variations has been performed, but would required lengthy documentation. It is useful to note that the first term on the left hand side of [1], and [3]-[6] are much smaller than the second when $P_{o} / P_{m s} \alpha \mathcal{V} / T \ll 1$ where $\mathcal{V}$ is the open volume in Big Bertha, $T$ is a period describing the time scale for the barometric pressure variations, $P_{r m s}$ is the standard deviation of the pressure variation and $P_{0}$ is the average pressure in Big Bertha1. So, an approximate solution can be obtained by integrating the differential equations, neglecting the first terms on the left hand side, and assuming that the mole fraction of gases inside Big Bertha is constant at all times.

Estimates for all the variables indicate that $P_{o}=29.23^{\prime \prime} \mathrm{Hg}$ and $P_{r m s}=0.203^{\prime \prime} \mathrm{Hg}$ (Crippen 1993, WHC-EP-0651). There are two possible choices for the appropriate volume. When the pressure changes, the gas inside the IXC's may expand, flow out of the IXC's and into the open area in Big Bertha. The result is that all gas in Big Bertha would participate in breathing. Alternatively, if the resistance to flow of the NUCFIL is large, the gas would flow very slowly out of the IXC's and only the gas outside the IXC's would participate. So, the two possible extremes for the volume are the internal volume in Big Bertha, excluding the volume occupied by the IXC's or total volume of inside Big Bertha including the gas in the IXC's. The larger volume provides the upper bound on the parameter, so we will use $\mathcal{V}_{\text {tot }} \approx 4.2 \mathrm{~m}^{3}$; this is the volume of a $75^{\prime \prime}$ tall $66.125^{\prime \prime}$ diameter container.

\footnotetext{
1 Note than this parameter can be small under several circumstances. First, the flow resistance may be small enough to ensure that the pressure inside Big Bertha is equal to the pressure outside Big Bertha. Second when very little air needs to move in and out either because the vessel is small or because are small. Or finally, when the pressure swings are slow, so that there is sufficient time for the air flow to occur.
} 
The magnitude of the resistance $\alpha$ is not known. Big Bertha was designed to hold pressure, and as such the resistance would normally be expected to be large. However, the vessel is flawed. Results of a pressure test indicate that at least 3.5 cubic $\mathrm{ft}$ of air were flow out of Big Bertha when $1 / 4$ psi of pressure is applied ${ }^{2}$. Based on this, the resistance is estimated to be

$\alpha=P_{\text {applied }} / P_{\text {atm }} Q<\frac{6.85 \times 10^{-2} / 4}{3.5 \mathrm{ft}^{3} / \mathrm{s} \times 0.3048^{3} \mathrm{~m}^{3} / \mathrm{ft}^{3}}=0.173 \mathrm{~s} / \mathrm{m}^{3}$.

The best time period $T$ to evaluate the parameter would be the integral time scale for barometric pressure variations. This was not calculated by Crippen. However, the upper. bound on the parameter $P_{o} / P_{m s} \alpha \mathcal{V} / T$ is obtained by using the shortest possible time scale that describes the rate at which barometric pressure changes occur. It is safe to say that fronts do not move across the Hanford site at a rate of more than 1 a day and so $T \gg 1$ days. Later discussion in this document will indicate that $T \sim 8$ days. Using these values, the parameter is found to be no greater than

$\frac{29.23^{\prime \prime} \mathrm{Hg}}{0.203^{\prime \prime} \mathrm{Hg}} \frac{\left(0.173 \mathrm{~s} / \mathrm{m}^{3}\right)\left(4.2 \mathrm{~m}^{3}\right)}{\left(24 \mathrm{hr} \times 8.64 \times 10^{4} \mathrm{~s} / \mathrm{hr}\right)}=5 \times 10^{-5} \ll 1$

For this value of the parameter, it is appropriate to use a simplified solution in which the mole fraction of gases in the Bertha are assumed to be constant. Note that even if fronts move across the site at a rate of 1 per hour, or even if the flow resistance is 100 times greater than estimated based on the pressure test, the simplified solution holds.

${ }^{2}$ Phone converstation with John Keve 2/10/95. 
The simplified solution follows. Readers should note that hydrogen concentration predicted by the following analysis contains one assumption that tends to under predict the hydrogen concentration when breathing is the only mechanism for hydrogen loss. As such, it is not inherently conservative. In this particular case, the error is on the order of 5 $\mathrm{x} 10^{-3} \%$ of the predicted value. (That is if a value of $1 \%$ is predicted, then the error due to this approximation is no larger than $0.00005 \%$ ). So, for this particular case, the simplifications in the breathing model are appropriate. Moreover, other conservatisms in the model, such as neglecting hydrogen loss due to permeation and diffusion will certainly result in a conservative estimate here.

Assume that the barometric pressure variations are the only cause for flow, and that they are described exactly by a sinusoidal variation ẉith period $T$ and amplitude $\Delta P$. Assuming that hydrogen concentration in Big Bertha is constant during an out breath, the total amount of hydrogen leaving Big Bertha during an out breath is approximately

$\chi_{H_{2}} N_{\text {out }}=\chi_{H_{2}} \mathcal{V}\left(\frac{\left(P_{o}+\Delta P\right)-\left(P_{o}-\Delta P\right)}{R T_{o}}\right)$

where $T_{o}$ is the temperature in Big Bertha and $P_{o}$ is the pressure in Big Bertha.

No hydrogen enters or leaves during an in-breath. Assuming that all hydrogen generated during one cycle leaves during one cycle, $N_{\text {out }}=\chi_{H_{2}} S_{H_{2}} T$. So, for small $\frac{P_{o}}{\Delta P}$ the hydrogen concentration will be

$\chi_{H_{2}}=\frac{S_{H_{2}}}{c_{o}}\left(\frac{P_{o}}{2 \Delta P}\right) \frac{T}{\mathcal{V}}$

Good values are available for the standard deviation of the pressure at the Hanford site , (Crippen, 1993). The relationship between the rms pressure fluctuations and the 
amplitude is $P_{m s}=\sqrt{2} \Delta P / 2$. The vessel is also at elevated temperature. Correcting for temperature the hydrogen mole fraction becomes

$\chi_{H_{2}}=\frac{S_{H_{2}}}{c_{a r m}} \frac{T_{o}}{T_{s p}}\left(\frac{P_{o}}{2 \sqrt{2} P_{m s}}\right) \frac{T}{\mathcal{V}}$

Again there is some ambiguity in the appropriate volume on which to base the estimate of the hydrogen mole fraction. The upper bound estimate for the hydrogen mole fraction in Bertha can be estimated by using the mininum possible volume that participates during breathing. The upper bound estimate is also achieved using the minimum possible concentration of gas, the maximum possible hydrogen generation rate in the individual IXC and the lowest possible estimate of the pressure variation and the slowest possible frequency of barometric pressure variations.

The minimum possible volume inside Big Bertha is estimated to be $2.103 \mathrm{~m}^{3}$; this is taken by finding the internal volume of a 75 in tall, 66.13 inch diameter vessel, and subtracting the outer volume of the six IXC's. The outer dimensions of an IXC are less than 75".tall and 19:13" in diameter. The source terms is obtained from Hawkes (1995), $S / C_{o}=9.93 e-$ 4 liters @ STP $/ \mathrm{hr}$. The root mean square of the pressure variations is reported to be 0.203 " Hg; the average pressure on the Hanford site was reported to be $29.2 "$ $\mathrm{Hg}$ (Crippen, 1993). For the previous estimate a time period of 1 day was selected as the a reasonable lower bound on the time scale for oscillations. However, for in this case, a conservative estimate requires the upper bound on the time period. The upper bound is estimated by assuming that the barometric pressure varies as a single sinusoid. For a single sinusoid; the following relationship holds $T=\frac{4 \sqrt{2} P_{m s s}}{|d P / d t|}$. Crippen (1993) reports $|d P / d t|=5.64 \times 10^{-3}$ " Hg/hour. So, $\mathrm{T}=203$ hours. Using this value 
$\chi_{H_{2}}=8.93 \times 10^{-4}$ liters $/ \mathrm{hr} \frac{298 \mathrm{~K}}{273 \mathrm{~K}}\left(\frac{29.2^{*} \mathrm{Hg}}{2 \sqrt{2} 0.203^{*} \mathrm{Hg}}\right) \frac{203 \mathrm{hr}}{2.1 \times 10^{3} \text { liters }}=10^{-3}=0.1 \%$

Based on these dimensions, the hydrogen concentration in the open volume in Big Bertha is estimated to be $<0.1 \%$. This value will be used as the boundary condition for the IXC analysis. Because this value is the upper bound, using this value as a boundary condition will tend to over predict the hydrogen values in other locations. However, the degree of over prediction due to this effect will be less than $0.1 \%$, and does not represent a major source of uncertainty.

\subsection{Transport of Hydrogen out of an IXC and into Big Bertha}

A conceptual sketch of an IXC is illustrated in figure 1. From the point of view of transport, the major features of the IXC are: 1) A plastic bag, 2) A NUCFIL filter, 3) a region consisting of stagnant air 4) an upper region consisting of drained resin in which the pore volume between resin beads is filled with gas, 5) a region consisting of saturated resin in which all the pore volume between beads is filled with water, and 6) a lower region consisting of air.

If any regions of saturated resin exist, then the major resistance to diffusion arises in the saturated resin. Both of the following conditions must occur in order for the resistance to diffusion to be high: 1) water must be contained in the region between individual resin beads and 2) the water must form a continuous horizontal sheet that prevents transport in the vertical direction. It seems unlikely that this is the case for a number of reasons. The resin was drained for 24 hours after the IXC's were decommissioned and the resin now sits on a wire screen. It is likely that water that did not drain during the first 24 hours drained from the resin during the approximately 4 years since the IXC's were 
decommissioned. Any water that has not drained may have evaporated, a very crude and conservative estimate of the water evaporation during the 4 years suggests that roughly $20 \%$ of the free water would have evaporated if the IXC's were at room temperature. Because the IXC's are radioactive, they are expected to be at elevated temperature, and free water should evaporate more rapidly.

Based on this information, it will be assumed that there are no regions of saturated resin. This in no way implies that the resin beads themselves are dry, but only that the interstitial space between resins is dry. The reader should note that this assumption is the major uncertainty associated with the predictions in this report.

If there is no saturated resin, then the major resistive features are the NUCFL filter and the plastic bag. All other resistive features contribute less than $2 \%$ to the total resistances. As such, neglecting these resistances during calculation represents round off. error.

A conservative estimate of the resistance of a NUCFIL filter was provided in Liljegren (1994). The estimated value was $R_{\text {nucfil }}=3.25 \times 10^{-4} \mathrm{sec} /$ liter.

From the point of view of transport, the plastic bag is both a diffusive barrier and a flow barrier. The bag is assumed to be a perfect flow barrier. The diffusion resistance of the plastic bag is estimated using a published value for the permittivity of LDPE, which is 7.4 $x 10^{-3} \mathrm{~cm}^{2} / \mathrm{s} \mathrm{Pa}$ (Goodfellow Corp.) The thickness of the bag is not known. However, the dimension for LDPE polymer films from Goodfellow Corporation range from 0.008 $\mathrm{mm}$ to $0.125 \mathrm{~mm}$. Thicker dimensions come in "sheets" and are suitable for use as bags. For analysis, I assumed that the thickness of the bag was $0.2 \mathrm{~mm}$ that should provide a very conservative estimate for the resistance. The cross-sectional are of the bag is at least 
equal to the outer surface area of the IXC. Based on these dimensions, the resistance of the bag is $R_{\text {plastic bag }}=1.08 \times 10^{-4} \mathrm{sec} /$ liter.

Because the plastic bags are assumed effective in preventing pressure induced flow, breathing does not reduce the predicted concentration in the IXC. Neglecting the permeation rate from the results in

$$
\begin{aligned}
& \chi_{H_{2}}=S_{H_{2}} / c_{s t p}\left(R_{\text {Nucifll }}+R_{\text {plastic }}\right) \frac{T_{o}}{T_{s p p}}+\chi_{H_{2}, \text { Berha }} \\
& =2.4 \times 10^{-4} \text { liter } / \mathrm{hr}(1.08+3.25) \times 10^{4} \mathrm{sec} / \text { liter } \frac{298 \mathrm{~K}}{273 \mathrm{~K}} \times \frac{1 \mathrm{hr}}{3600 \mathrm{~s}}+0.001
\end{aligned}
$$

$=0.004=0.4 \%$

So, the upper bound estimate for hydrogen mole fraction anywhere in Big Bertha or the IXC's contained in Big Bertha is $<0.4 \%$. It is likely that the mole fraction is lower.

\section{References}

Crippen, M.D. 1993, "Barometric Pressure Variations" WHC-EP-0651.

Hawkes, Eric, "Gas Generation Rates in Six 105-KW Ion Exchange Columns" (Draft) Letter to Lucia Liljegren, Feb. 27, 1995.

Liljegren, L.M. 1995, PNL-IX-IR-0006, "Estimate of Hydrogen Concentration in KW14".

GoodFellow Corp. Jan. 19, 1995 Fax Describing Properties of Plastics. 


\section{DISPOSITION PROJECT}

DOCUMENT APPROVAL FORM

Title:

Needs to Flush IXM's to Eliminate Hydrogen Gas

Document Number: PNL-IX-IR-0017

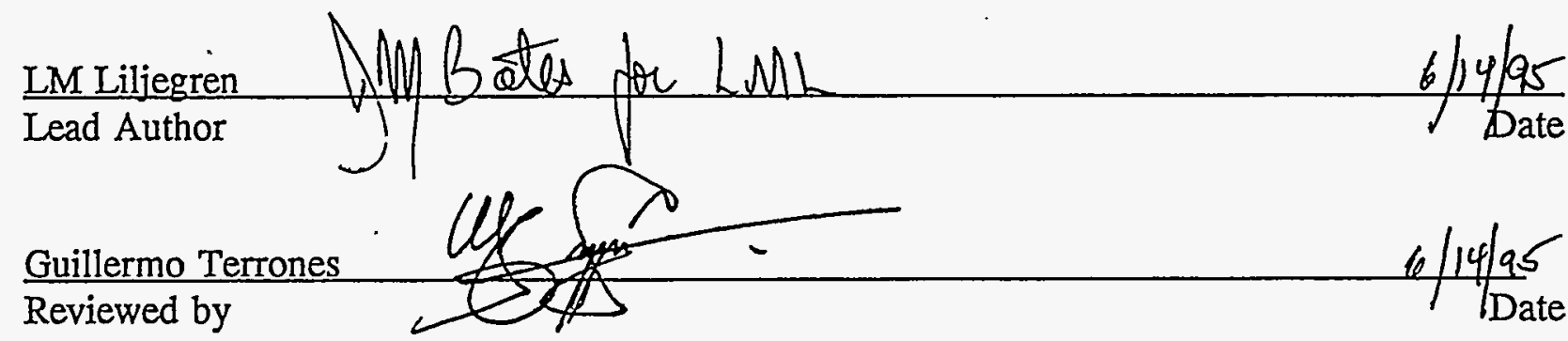
JM Bates
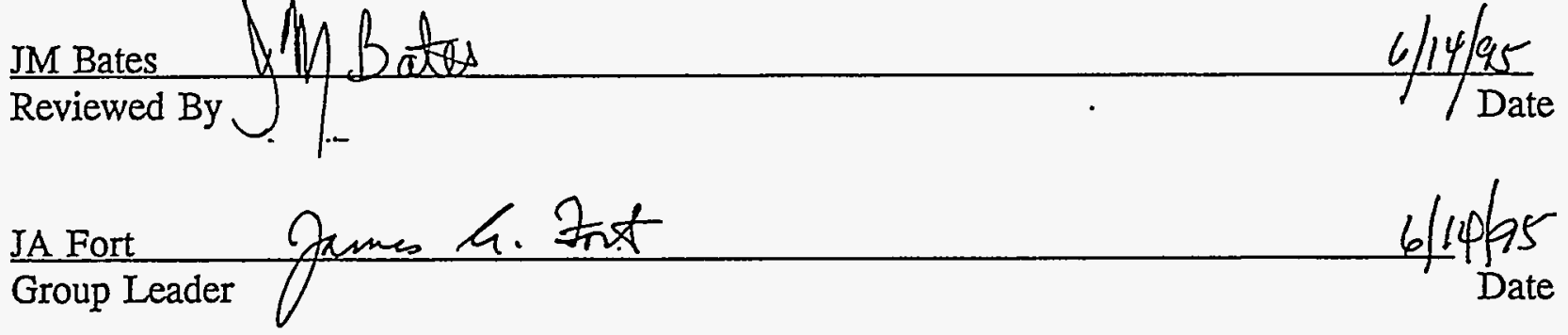
Needs to Flush IXM's to Eliminate Hydrogen Gas

L. M. Liljegren

June 141995

Pacific Northwest Laboratory

Richland WA 99352 
To:

From: $\quad$ Lucia Liljegren

Subject: $\quad$ Need to Flush IXM's to Eliminate Hydrogen Gas.

Date: $\quad$ June 13, 1995

\section{SUMMARY:}

If the criterion for a safe move is a hydrogen mole fraction less than $25 \%$ of the LFL, then flushing to reduce the hydrogen mole fraction below the LFL is not required for 94 days after an IXM is decommissioned. This recommendation is based on a conservative model that uses the results of sampling to determine the time constants for an intact IXM.

The hydrogen mole fraction during the time immediately after an IXM is decommissioned was estimated using 3 methods. The methods are:

1) Very conservative: Assumes that the hydrogen gas generation rate will not exceed $1.19 \mathrm{x}$ 10-2 liter @ STP/hr. This is the predicted generation rate of an IXM with the radiological dose of $\mathrm{KE}-11$.

2) Conservative: Estimates time constants from sample data from three IXM's. Also assumes that the hydrogen mole fraction in the newly decommissioned IXM will eventually reach $100 \%$.

3) Most Plausible: Estimates time constants from three IXM's, and further assume that the hydrogen mole fraction will never exceed $27.5 \%$ at steady state. This is the worst case estimate for a steady state hydrogen mole fraction in an LXM and is based on a hydrogen generation rate of $1.19 \times 10^{-2}$ liter @ STP/hr.

The first method of estimating the hydrogen mole fraction during a transient does not use any results from sampling of the IXM's. The second two use the sample data from the IXM's to refine the estimate of the time constants for the IXM.

The number of days that the $\mathrm{H}_{2}$ mole fraction is predicted to remain below $1 \%, 2 \%$ and $4 \%$ is summarized in Table 1.

Table 1. Results of Three Transient Analyses.

\begin{tabular}{|l|c|c|c|}
\hline $\begin{array}{l}\text { Number of days that the mole fraction of hydrogen in the } \\
\text { open volume of the IXM will remain below: }\end{array}$ & $1 \%$ & $2 \%$ & $4 \%$ \\
\hline $\begin{array}{l}\text { Very Conservative: Hydrogen generation rate is assumed } \\
\text { to be less than in KE-11. }\end{array}$ & $\begin{array}{c}15.5 \\
\text { days }\end{array}$ & $\begin{array}{c}31 \\
\text { days }\end{array}$ & $\begin{array}{c}65 \\
\text { days }\end{array}$ \\
\hline $\begin{array}{l}\text { Conservative: The time constants from sample data; the } \\
\text { hydrogen generation rate is assumed to be sufficient to } \\
\text { allow the mole fräction to eventually reach 100\%. }\end{array}$ & $\begin{array}{c}94 \\
\text { days }\end{array}$ & $\begin{array}{c}137 \\
\text { days }\end{array}$ & $\begin{array}{c}199 \\
\text { days }\end{array}$ \\
\hline $\begin{array}{l}\text { Most Plausible: The time constant is estimated from } \\
\text { sample data; the hydrogen generation rate is assumed to be } \\
\text { less than in KE-11. }\end{array}$ & $\begin{array}{c}189 \\
\text { days }\end{array}$ & $\begin{array}{c}280 \\
\text { days }\end{array}$ & $\begin{array}{c}427 \\
\text { days }\end{array}$ \\
\hline
\end{tabular}

Although estimating method 3 is most plausible, there is some uncertainty associated with the estimates based on sample data. This is due to the small number of available data points. For the purposes of deciding whether to flush to remove excess hydrogen, I recommend using the estimates described in method 2, that is the "conservative" model above. 


\section{LIMITATION:}

The transient behavior of the IXM's was estimated based on available sampling data. The transient behavior can be described using a function with three adjustable parameters, one of which may be predicted from the resistance of the NUCFIL and the volume of air in the IXM. The other two must be estimated based on data. Data from 3 sampled IXM's was used. One unit, KE-11, was excluded because it appears to "breathe" through some path other than the NUCFL. As a result, the data from that unit could not be reconciled with the time dependent behavior of the other three units. Another unit, KE-14, was excluded because its behavior also could not be reconciled with the other units. This unit was run past exhaustion, and it is possible that the radionuclide loading estimate or some other feature is anomalous.

Because only three data points are being used to estimate 2 parameters, there is a significant amount of uncertainty in determining the function that describes the transient behavior of an IXM. However, the following features suggest that the limitation is not severe:

1) If the data from either $\mathrm{KE}-11$ or $\mathrm{KE}-14$ were incorporated into the analysis described here, the estimated time constants would be longer and the hydrogen mole fraction at any time would be predicted to be lower. So, the "safe" period for the IXM's would be predicted to be longer. To be conservative, the data was ignored until further investigation allows it to be treated with greater confidence.

2) The time of the "safe" window was found to be relatively insensitive to the exact value of the fitting parameters selected, provided that the pair parameters are reasonably consistent with the data. Specifically, the time required for the hydrogen mole fraction to reach $4 \%$ was found to be 195 days for a case where the time constant was assumed to be $\tau=3$ years and $\alpha$ $=0.31$ instead of 199 days predicted using the "best" values of $\tau=640$ days and $\alpha=0.992$ on which the recommendations in this document are based.

\subsection{TRANSIENT BEHAVIOR}

The transient behavior of the hydrogen mole fraction in an IXM can be examined at several levels. Section 1.1 discusses a lumped parameter model with the IXM treated as. two regions. Section 1.2 discusses a simplification that occurs when the resistance between the lower region and the upper region goes to zero, and the system acts a single open region connected to the atmosphere through the NUCFIL. This simplification provides an estimate of the hydrogen mole fraction that is always larger than predicted by the more detailed model in 1.1. The advantage of the simplified model is that the predictions do not rely on experimental determination of the time constants. Section 1.2 also provides a very conservative estimate of the hydrogen mole fraction during a transient. Section 1.3 uses data to estimate the parameters in the full model. Using the sample data provides more refined estimates of the time constants and results in longer estimates of the "safe" window. Section 1.4 describes why data from $\mathrm{KE}-14$ was not used.

\subsection{Full model}

Each IXM contains six cylindrical units each of which contains damp resin. The six individual units are interconnected by a piping network, which is ultimately connected to the atmosphere through a NUCFIL filter. The filter allows some flow and molecular diffusion to the atmosphere. An idealized sketch of an IXM is illustrated in Figure 1; this sketch shows one unit connected to the atmosphere through one NUCFIL.

To develop the transient model, the internal components of the IXM are divided into regions 1 and 2. Region 1 consists of all the gas in the open volume and any portions of very well drained resin. Region 2 consists of resin that contains a large fraction of water in the pores 
between individual resin beads. Conceptually, this division is reasonable because diffusion in the gas space and the dry resin region is much more rapid than diffusion in regions of very wet resin. However, the exact physical location of the division between the regions is not known, because it depends on the location of the saturation line.

A transient model based on this idealization was developed using the following assumptions:

1) The major resistance to molecular diffusion and flow between the open volume in all IXM's and the atmosphere is the NUCFIL. This is equivalent to assuming that the gas composition in the open volume is identical for all IXM's. This assumption is known to be correct based on estimates of the resistance to diffusion of the piping compared to the NUCFIL (Liljegren 1995).

2) The gas composition is identical in the void spaces of all six individual resin beds. This will be approximately true when the gas compositions in the open volumes above the resin beds are identical and gas is generated at equal rates in each resin bed.

3) The pressure in the vessel is approximately constant at all times. This is expected to be true because pressure induced flow occurs relatively freely through the NUCFIL.

4) All hydrogen is generated in the resin bed; none is generated in the open volume. This is expected to be true because hydrogen generation due to radiolisis occurs in regions containing water. Very little water exists in the open volume.

These assumptions allow the IXM to be treated as a single unit with one connection to the atmosphere, rather than 6 units with complicated interconnections to the atmosphere.

Based on these assumptions, Hydrogen balances can be written for 1) the open volume and 2) the resin bed. The hydrogen balance for the open volume is

$V_{1} c \frac{d \chi_{1}}{d t}+c \frac{\chi_{1}}{R_{1}}+c \frac{\chi_{1}-\chi_{2}}{R_{2}}=0$

where $V_{1}$ is the volume of the open volume, $c$ is the molar concentration of gases in the IXM's, $R_{1}$ is an effective resistance for the flow of hydrogen through the NUCFIL, $R_{2}$ is the effective resistance for flow out of the resin bed and into the open volume, $\chi_{2}$ is the hydrogen mole fraction in the resin bed and $\chi_{1}$ is the hydrogen mole fraction in the open volume.

The effective resistances account both for diffusion resistance and flow resistance. When pressure driven flow is unrestricted and flow occurs only to allow gases generated in the IXM to leave the IXM it can be shown that

$$
R_{1}=\left(\frac{1}{R_{\text {nucfll }}}+\frac{S_{H_{2}}}{c}\right)^{-1}
$$

where, $R_{n u c f l}^{-1}$ is the diffusion resistance of the NUCFIL in units of time/volume. 


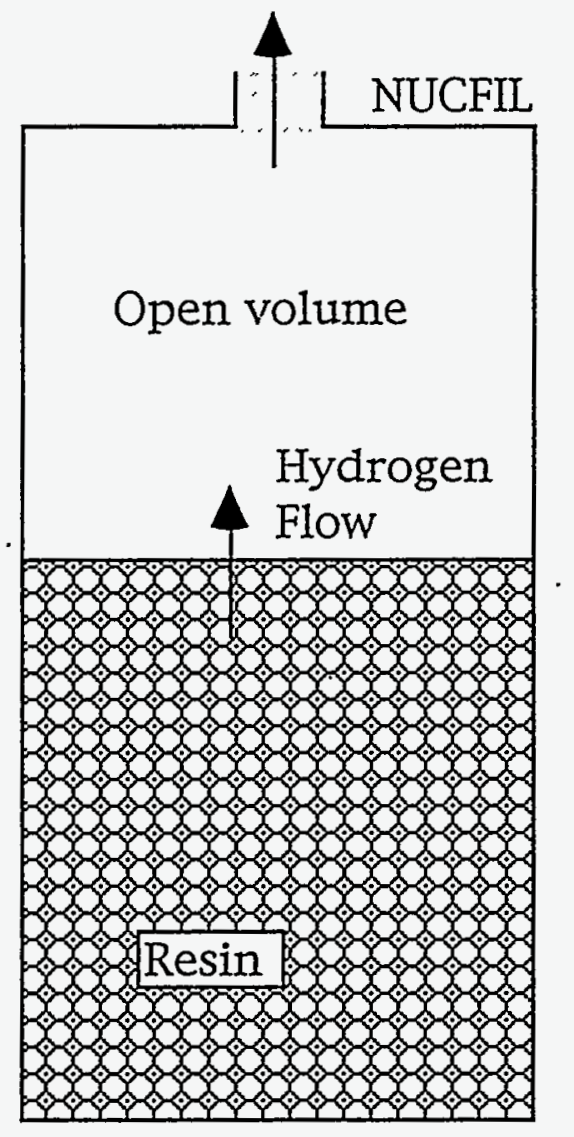

Atmosphere:

Boundary Condition

Hydrogen concentration $=0$

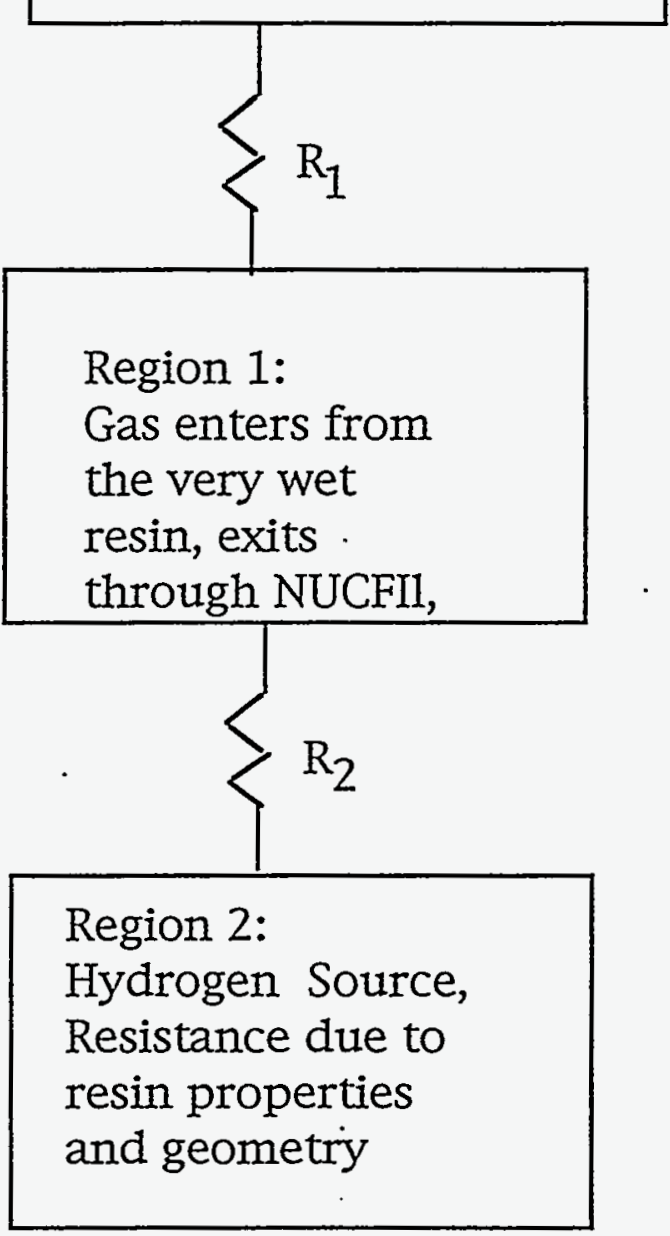

Figure 1. Idealized Model of an IXM.

The first term in the equation represents the time rate of change of moles of hydrogen in the open volume. The second represents the rate at which moles of hydrogen are lost to the atmosphere; it was assumed that there is no hydrogen in the atmosphere. The third term represents the rate at which moles of hydrogen enter the open volume from the resin bed, where it is generated.

Time $t=0$ corresponds to the time when the unit is first drained. At that time it is assumed that the hydrogen mole fraction is zero, So $\chi_{1}=\chi_{2}=0$ at $t=0$. Note hydrogen gas will not enter region 1 until after the mole fraction in region 2 rises. So, obviously, the final solution will have a slope of $\frac{d \chi_{1}}{d t}=0$ at $t=0$. 
The hydrogen balance in the resin bed is described using

$V_{2} c \frac{d \chi_{2}}{d t}+c \frac{\chi_{2}-\chi_{1}}{R_{2}}=S_{H_{2}}$

where $V_{2}$ is the volume of gas in the pore spaces of the resin bed and $S_{H_{2}}$ is the rate at which hydrogen is generated in moles/time.

The first term represents the rate of accumulation of hydrogen in the resin bed. The second describes the rate at which hydrogen enters the open volume, or leaves the resin bed. The term on the right hand side describes the rate at which hydrogen is generated, in Moles/ time.

The steady state solution to this system of equations is

$\chi_{\text {linf }}=S_{H_{2}} R_{1} / c$ and $\chi_{2, \text { inf }}=S_{H_{2}}\left(R_{2}+R_{1}\right) / c$.

There are two general solutions to equations [1] and [2]. Both are decaying exponentials of the form $\chi_{\text {linf }}=C_{1} \exp (-t / \tau)$ and $\chi_{2 \text { inf }}=C_{2} \exp (-t / \tau)$ where $C_{1}$ and $C_{2}$ are constant and $\tau$ is a time constant. The time constant in the solution is an algebraic function of the volumes and. resistances of the system. There are exactly two permissible values of the time constants that achieve a general solution to [2] and [3]. To match the initial conditions, the solution for the mole fraction in each region is the sum of three quantities: 1) the steady state solution, 2) an exponential with a time constant $\tau_{1}$ and 3 ) a second exponential with time constant $\tau_{2}$. The second time constant can be expressed as some multiple of the first time constant and $\alpha$ as $\tau_{2}$ $=\alpha \tau_{1}$.

It can be shown that the solution for the mole fraction in the open volume is:

$\chi_{1}=\chi_{1 \text { inf }}\left\{1-\frac{\exp (-t / \tau)}{1-\alpha}+\frac{\alpha \exp (-t / \alpha \tau)}{1-\alpha}\right\}$

where $\tau=\tau_{1}=\lambda_{1}^{-1} ; \tau_{2}=\lambda_{2}^{-1} \alpha=\tau_{2} / \tau_{1} ; \lambda_{2}=\frac{-b+\sqrt{b^{2}-4 d}}{2} ; \lambda_{1}=\frac{-b-\sqrt{b^{2}-4 d}}{2}$

and $b=-\left[\left(R_{1} V_{1}\right)^{-1}+\left(R_{2} V_{1}\right)^{-1}+\left(R_{2} V_{2}\right)^{-1}\right] d=\left(R_{1} V_{1}\right)^{-1}\left(R_{2} V_{2}\right)^{-1}$.

Figure 2 illustrates a time dependent model with $\alpha=0.992$ and $\tau=640$ days. Note that the function has the following properties: 1 ) The normalized hydrogen mole fraction, $\chi_{1} / \chi_{1, \text { inf }}$, approaches one as time goes to infinity. 2) The hydrogen mole fraction at time zero is zero. 3) The derivative of the mole fraction is zero at time zero. 4) The second derivative at time zero is equal to $\chi_{1 \text {,inf }} /\left(2 \tau_{1} \tau_{2}\right)=1 /\left(2 \alpha \tau^{2}\right)$. So $\alpha$ near 1 means that the system takes a relatively long time before its mole fraction behaves like a decaying exponential. In contrast, $\alpha$ near zero occurs when one region is much more resistive than the other, and so quickly dominates the transient behavior. 


\section{Possible curve fits to dal}

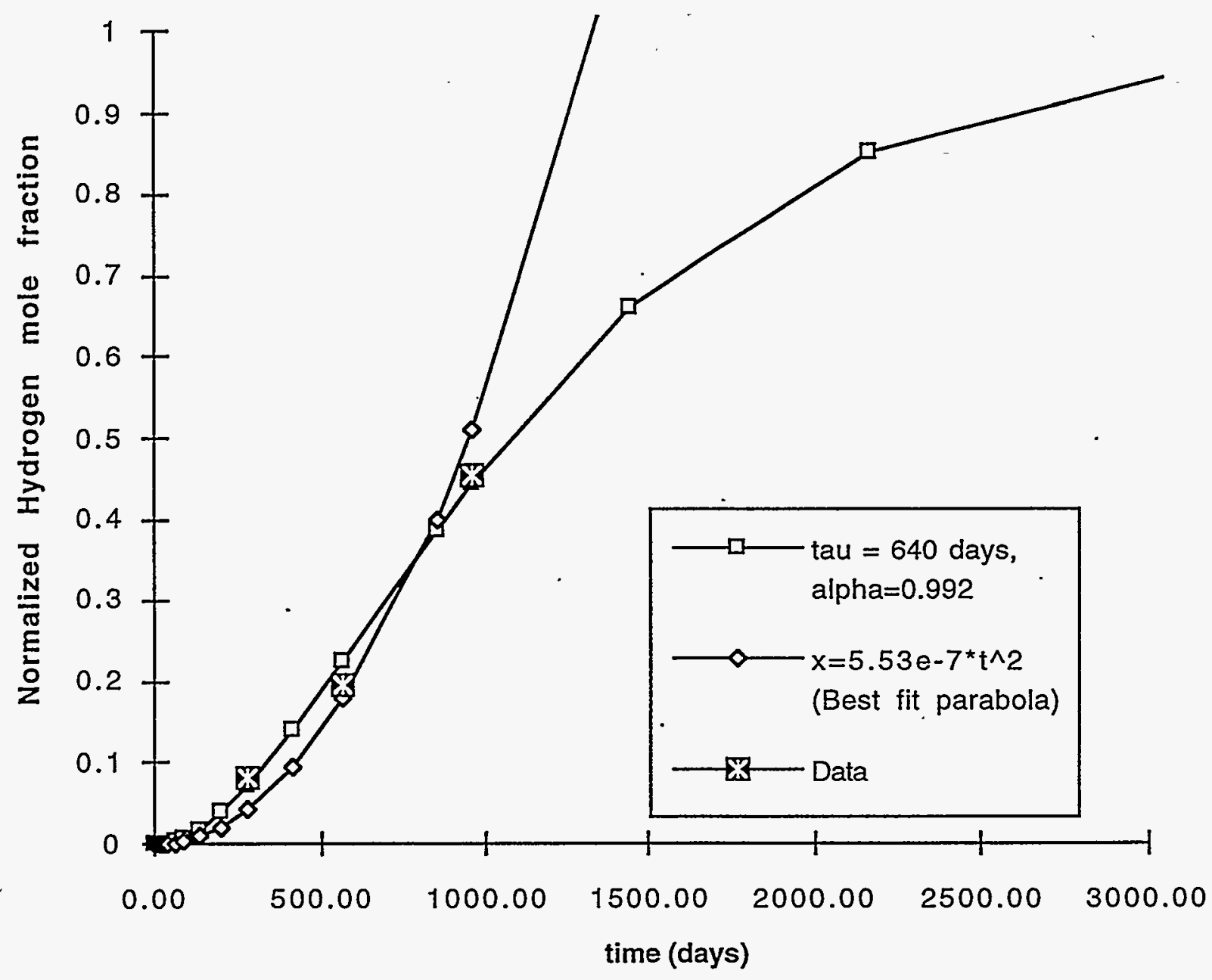

Figure 2. Comparison of Curve Fits and Data.

Physical systems are constrained to have positive time constants, so $0<\tau_{1}$ and $0<\tau_{2}$. The parameter, $\tau$ has arbitrarily been selected as the larger of the two time constants. So, ratio of the two time constants, $\alpha$, falls between 0 and 1 ; i.e. $0<\alpha<1$. There is a very large range of physically plausible values of $\alpha$ and $\tau$ for IXM's. For IXM's, lower values of $\tau$ always imply relatively dry resins which allow rapid diffusion of hydrogen. This occurs because the time constant is always smallest when gas can diffuse easily from the system; note that this is reflected algebraically by resulting in larger the values of $b$. Low values of $\tau$ with small values of $\alpha$ correspond to the driest possible resins. Relatively low values of $\tau$ with $\alpha$ very near 1 correspond to a resin that is generally dry but has a very tiny layer of saturated water 
at the bottom. Large volumes of saturated resins would result in very high values of $\tau$ with very low values of $\alpha$. This occurs because the resistance and volume of the resin becomes dominant.

\subsection{Simplified solution : Upper bound estimate}

The following discussion describes a method to obtain conservative predictions for the hydrogen mole fraction in the upper volume. It corresponds to the exact result when the resistance for gas diffusing out of resin is zero. It is possible to show that the solution to this problem always overpredicts the hydrogen concentration in the open volume compared to the prediction from the full problem. In addition, this solution can be evaluated when the only features that are known with confidence is the total volume of gas in the IXM and the gas generation rate. The hydrogen mole fraction in region 1 will rise most quickly during the initial transient when the gas flows very freely out of the resin. In this case, the solution to the set of equations described in 1.1 simplifies to

$\chi_{1}=\chi_{1 \text { inf }}\{1-\exp (-t / \tau)\}$

where, $\tau=R_{1}\left(V_{1}+V_{2}\right)$ and $\chi_{1 \text { inf }}=S_{H_{2}} R_{1} / c$.

This is equivalent to $\alpha=0$ occurring because the only resistance is $R_{1}$.

The magnitude of $R_{1}$ can be estimated based on physical properties of the NUCFL and on the estimated gas generation rate. The relation $R_{1}=\left(R_{n u f f i}^{-1}+S_{H_{2}} / c\right)^{-1}$ is provided in Liljegren (1995). The hydrogen accumulates most rapidly when gas is generated at the maximum possible rate and for the maximum possible magnitude of $\mathrm{R}_{\mathrm{NUCF}}$. These are estimated to be $S_{\mathrm{H}_{2}} / c_{o}<1.19 \times 10^{-2}$ liter @ STP/hr where $c_{o}$ is the molar concentration of gas at STP and $R_{\text {nuffil }}<1.05 \times 10^{5} \mathrm{sec} / \mathrm{liter}$.

The estimate for an IXM from day 1 to day 100 after decommissioning based on $S_{H_{2}} / c_{o}=$ $1.19 \times 10^{-2}$ liter @ STP/hr and various values of $R_{\text {nuffil }}$ are shown on Figure 3. For $R_{\text {nucfil }}=$ $1.05 \times 10^{5}$, the hydrogen mole fraction could reach $1 \%$ in 15.5 days, $2 \%$ in 31 days and $4 \%$ in 65 days.

\subsection{Refinement based on data.}

Further analysis was performed to estimate the magnitudes of $\tau$ and $\alpha$ based on data. Figure 2 illustrates a-curve of form [4] with $\tau=640$ and $\alpha=0.992$; three data points from KW-14, KE-12 and E94-03 are compared to this curve. Because the transient behavior at very small times based on [4] corresponds to a parabola that passes through zero, Figure 2 also illustrates the best fit parabola of the form $\chi_{1} / \chi_{1, \text { inf }}=a t^{2}$. All hydrogen mole fraction data are normalized by the predicted steady state value, so the "y" axis corresponds to $\chi_{1} / \chi_{1, \text { inf }}$. Each measured mole fraction is within $10 \%$ of the magnitude predicted by the algebraic function. So, the data fits the functional form relatively well, but not perfectly. Note however that this is a two parameter fit using three data points, and so the uncertainty in the fit is very large. 


\section{Effect of estimate of RNUCFIL on number safe days}

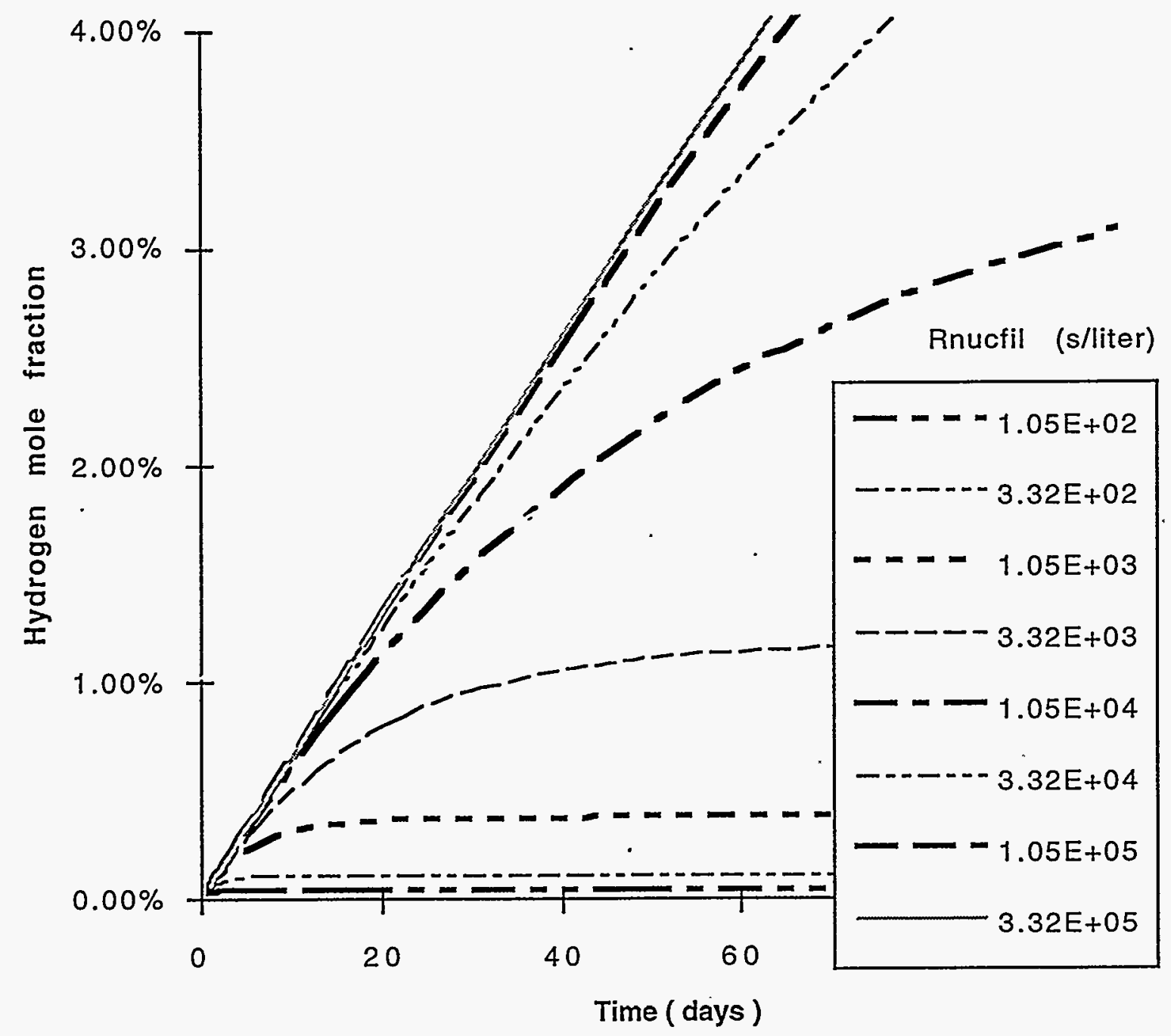

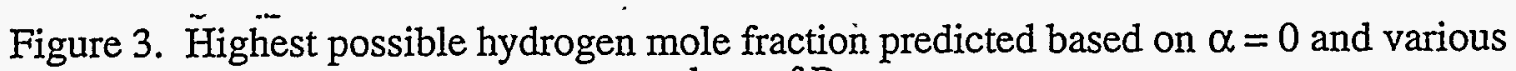
values of $R_{1}$.

The maximum mole fraction of hydrogen on any day predicted using either curve fit is illustrated in Figure 4; this is a detailed view of Figure 2. For hydrogen mole fractions of interest in safety analyses, the full functional form provides higher estimates of the hydrogen mole fraction than the parabola. Based $\alpha=0.992, \tau=640$ and $\chi_{\text {inf }}=100 \%$, the mole fraction of hydrogen will be $\chi \operatorname{IXM}(94$ days $)=1.0 \% ; \chi \operatorname{IXM}(137$ days $)=2.0 \%$ and $\chi_{\operatorname{IXM}}(199$ days) $=4.0 \%$. 
Even longer safe periods could be justified by observing that the hydrogen mole fraction is never expected to reach $100 \%$ in any IXM. The highest mole fraction measured to date is < $11 \%$ hydrogen. The maximum predicted mole fraction in the open volume of an intact IXM was $<27.5 \%$, which is predicted for an intact IXM with the radiological inventory of KE-11. If the parameters $\tau=640$ days and $\alpha=0.992$ hold, and the maximum hydrogen mole fraction for an IXM is limited to $27.5 \%$, then the maximum possible hydrogen mole fractions will be $\chi_{\mathrm{IXM}}<1 \%$ for 189 day, $\chi_{\mathrm{IXM}}<2 \%$ for 280 days and $\chi_{\mathrm{IXM}}<4 \%$ for 427 days.

The final estimates are probably the closer estimates of the correct number of days before a high dose rate IXM will exceed the $1 \%, 2 \%$ and $4 \%$. However, the estimates are not inherently conservative. Uncertainties in the magnitude of the fitting parameters $\alpha$ and $\tau$ allow the hydrogen mole fraction to be underestimated. Because there are very few conservative factors in this final estimate, it should not be used until the time constants for the IXM's can be determined from a larger data base.

\subsection{Comment on KE-14.}

Data from KE-14 indicate that either the hydrogen mole fraction is rising more slowly in this IXM than in others or the hydrogen mole fráction will not reach the predicted level near $24 \%$. The data could not be reconciled even approximately with data from other IXM's. All possible reasons have not been explored. However it is possible that:

1) The estimate for the radionuclide inventory in that unit is incorrect.

2) The method of estimating the hydrogen generation rate for that unit provides poorer predictions than for other units.

3) The unit has some opening to the atmosphere other than the NUCFI.

Based on the history of this IXM, reasons 1 and 2 may be plausible. I have found no evidence to suggest reason 3 . 


\section{Minimum time to reach $1 \%, 2 \%$ and $4 \%$ mole fraction}

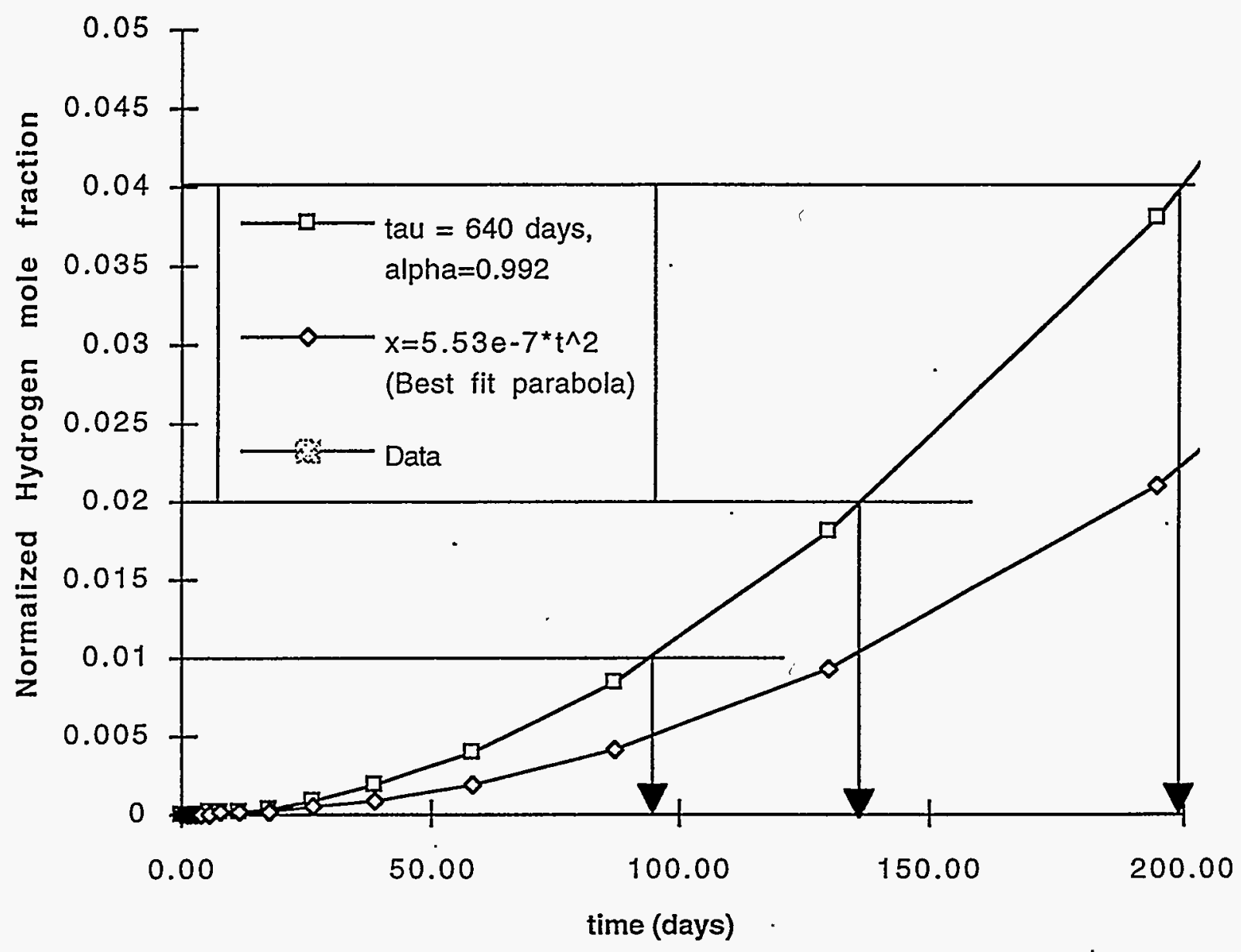

Figure 4: Variation of Hydrogen Mole Fraction During Initial Transient. 


\section{APPENDIX: BOUNDS ON $\tau$ BASED ON DRY AND WET RESIN}

Examining the extremes of $\tau$ for dry and wet resin it is possible to show that 414 days $<\tau<$ 164 years. Examining the extreme possible behavior when the resin is dry provides an estimate of lower bound on the time constant $\tau$. Examining the wet case provides the upper bound on $\tau$. The range is extremely large due to the difference in diffusivity of hydrogen through water and through air.

\section{Dry resin.}

Suppose that the resin is very dry , then the resistance of the resin is very low. For this case, the resistance of the NUCFI is larger than the resistance of the resin bed.

So, $R_{1}>R_{2}$. For most extreme possible case, $R_{2}=0$ and the lower resin bed comes to equilibrium with the gas in the upper volume very quickly compared to rate at which the open volume comes into equilibrium with the atmosphere. In this extreme, the whole IXM would act like a single well mixed space with a uniform gas concentration.

The total gas volume in the six modules of an IXM is approximately $0.47 \mathrm{~m}^{3}$; this volume includes the gas in the pore spaces between resin beads and the volume in the open area above the resin. The resistance of the NUCFLL and piping network is approximately $R_{\text {ruffil }}=$ $1.05 \times 10^{5} \mathrm{sec} / \mathrm{liter}$, recall $R_{1}=\left(R_{\text {nucfil }}^{-1}+S_{\mathrm{H}_{2}} / c\right)^{-1}$. So, the upper range for the time constant with a completely dry resin can be obtained by neglecting the gas generation rate. In which case $\tau=0.47 \mathrm{~m}^{3} \times 1.05 \times 10^{5} \mathrm{sec} /$ liter $\times 1000 \mathrm{liter} / \mathrm{m}^{3}=4.9 \times 10^{7} \mathrm{sec}=1.37 \times 10^{4}$ hours $=$ 571 days. Accounting for the maximum plausible gas generation rate for an IXM of $1.19 \mathrm{x}$ $10^{-2}$ liters/hr and assuming the IXM is at $25 \mathrm{C}$ results in $\tau=414$ days. Higher values of $\tau$ are expected for finite values of $R_{2}$. Slightly lower values could occur if there is significant breathing; in which case, the final hydrogen mole fraction in the IXM's will also be much lower than predicted using current models. But, time constants near this value are plausible and correspond to relatively dry resins.

\section{Wet Resin}

Examining the wet case provides the upper possible bound on $\tau$. If the resin is very wet, then resistance to diffusion in the resin will be very large. However, the effective resistance is affected by two terms and obeys $R_{2}=\left(R_{r e s i n}^{-1}+S_{H_{2}} / c\right)^{-1}$. So the largest possible effective resistance is $R_{2}<\left(S_{H_{2}} / c\right)^{-1}$; this means that hydrogen can leave by flowing, rather than diffusing, out of the resin bed. Strictly speaking, this resistance could be infinite in the IXM's that have zero radiological loading. Maximum possible resistance for an IXM that has been sampled to đate occurs for IXM- KW 14 and is $R_{2}<\left(S_{H_{2}} / c\right)^{-1}=(3.27 \mathrm{e}-4$ liters @ STP $/ \mathrm{hr})^{-1}=3058$ hours $/$ liter. The time constant based on this estimate would be $\tau=3058$ hours $/$ liter 470 liters $=1.44 \times 10^{6}$ hours $=6.0 \times 10^{4}$ days $=164$ years. This establishes the upper bound on the time constant that might be consistent with data.

\section{REFERENCE}

Liljegren, Lucia, 1995 "Estimate of Hydrogen Concentration in KW-14" PNL-IX-IR-0006. 
From: $\quad$ Guillermo Terrones

To: $\quad$ Bill Mills

Date: $\quad$ July 10, 1995

Subject: Flammability Limits of Hydrogen in the IXM's

It was recently required to identify the lower flammability levels of hydrogen in oxygen-depleted air mixtures. The possibility of having oxygen depletion inside the IXM's and the generation of other flammable gases may affect the flammability limits. The most comprehensive experimental data on the flammability of hydrogen in mixtures of oxygen and nitrogen was reported by Jones (1929) (see Appendix). Jones also validated the formula of Le Chatelier for the mixtures he studied and proposed a generalization of this formula to calculate the limits of flammability for gaseous mixtures. The seminal paper of Jones on the inflammability of mixed gases has been cited in numerous papers and in the classic text on combustion of Lewis and von Elbe (1987). A theoretical approach to determine the lower flammability limits of hydrogen, oxygen, and a diluent was proposed by Shebeko et al. (1984) based on the molar enthalpies and the diffusion coefficients of the constituents.

Liljegren performed several analyses to estimate the concentration of hydrogen in the IXM's. Her estimates showed levels of hydrogen in the IXM's on the order of $1 \%$ or less which are below the lower flammability limit of hydrogen in air $(4.1 \%)$. In the estimates that follow, it will be assumed that there is oxygen depletion inside the IXM's and that vapor of carboxylic acid is formed.

In a recent memo from $P$. K. Melethil (May 1995) it is stated that oxygen is depleted by reacting with the aliphatic fragments in the polymer to yield carboxylic acid. The depletion of oxygen is estimated to be less than $1 \%$ per year at $35^{\circ} \mathrm{C}$. In addition to the generation of hydrogen and oxygen by radiolysis within an IXM, we can have the simultaneous depletion of oxygen and the production of carboxylic acids at a very slow rate. The final oxidation product is carbon dioxide. We do not know the exact temperature inside the IXM's, thus we do not have a precise figure for the molar rate of depletion of oxygen due to reaction with aliphatic fragments. However, we can determine the flammability limits of hypothetical flammable mixtures of oxygen-depleted air formed within the IXM's.

Let us investigate the worst case scenario of oxygen depletion within a typical IXM for which hydrogen is produced at the rate of $10^{-3}$ liter $/ \mathrm{hr}$ under the following assumptions:

1) The final product of the oxidation of aliphatic fragments is a carboxylic acid which will be assumed to be in vapor form within the IXM's. Even though the shorter-chain carboxylic acids are liquids at room temperature (boiling point $>100^{\circ} \mathrm{C}$ ) only a fraction of these acids will be in form of vapor. 
2) Let us assume that oxygen concentration can increase or decrease by $2.3 \%$ from the original content of oxygen in air. It is unlikely that the content of oxygen can decrease to less than $18.7 \%$ because the rate of production of oxygen by radiolysis is much greater than its depletion by aliphatic fragment oxidation.

3) The lower flammability limit of a typical carboxylic acid such as acetic acid vapor in air is $5.4 \%$. According to Le Chatelier's formula for a mixture of hydrogen and acetic acid vapor in air, the lower flammability limit of this mixture will vary from $4.1 \%$ to $5.4 \%$. Let us assume that the carboxylic acid vapor is as flammable as hydrogen.

\section{SAMPLE CALCULATION}

To estimate the excess concentration of oxygen, we assume that there is no oxidation of the aliphatic fragments. We also assume that hydrogen is produced at the rate of $10^{-3}$ liter/hr. The transport of gases that takes place inside the IXM which ultimately leads to its diffusion to the atmosphere can be modeled as a network of gas sources and diffusive resistances $R_{1}, R_{2}$, and $R_{3}$ for the piping and filter elements as shown in Fig. 1. The total molar rate of hydrogen produced by the IXM is $6 \mathrm{~N}=$ $\mathrm{N}_{\mathrm{IXM}}$, and that of oxygen is $0.5 \mathrm{~N}_{\mathrm{IXM}}$.

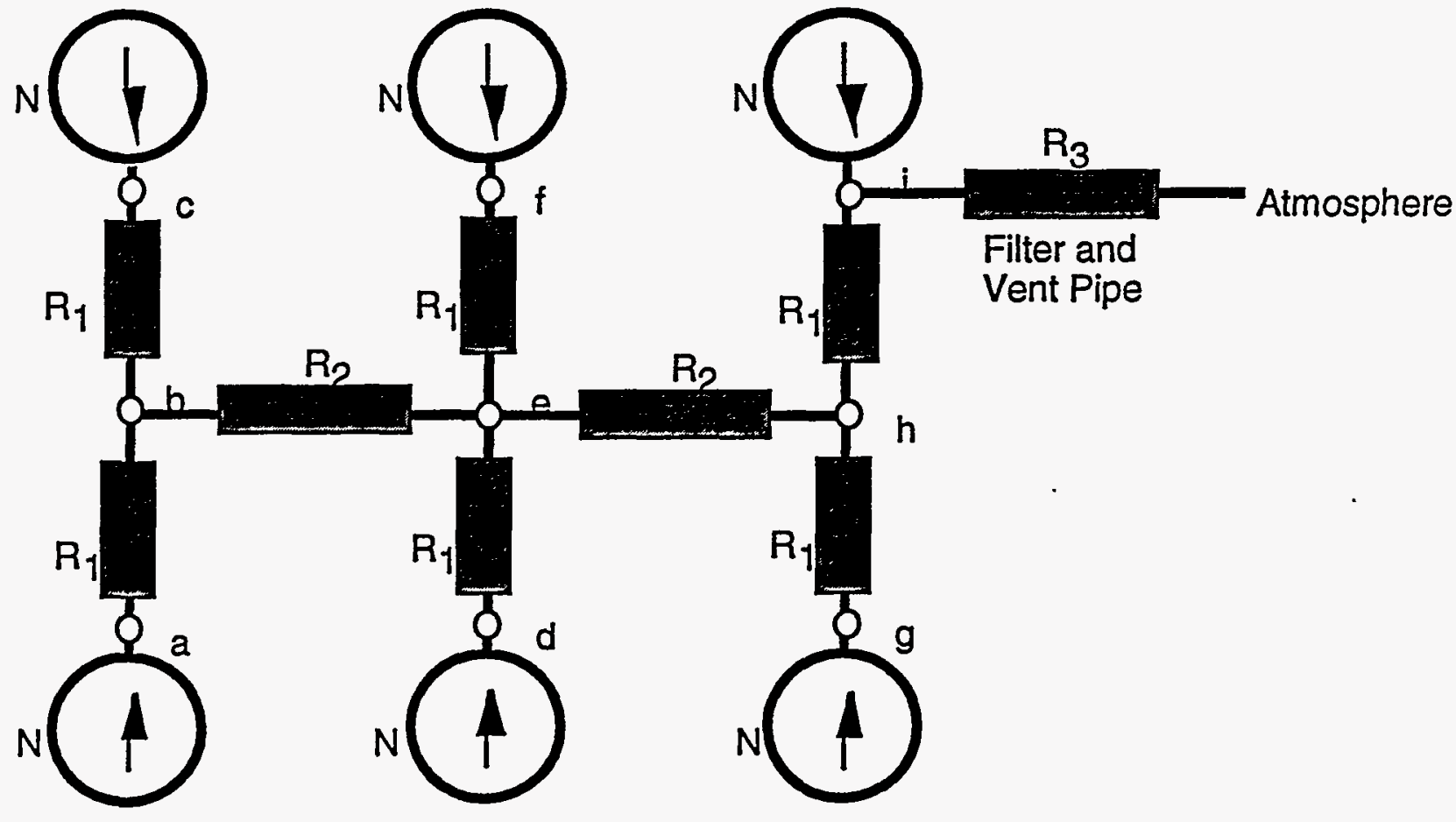

Figure 1. Schematic representation of the elements in the IXM. 
The unknown gas concentrations $C_{x}(x=a, . . ., i)$ at each node can be expressed in terms of the known resistances and the molar sources $\mathrm{N}$. A node-concentration analysis yields that the highest concentration of hydrogen $C_{1}$ and oxygen $C_{2}$ occur at nodes $a$ and $c$

$$
C_{1}=2 C_{2}=N_{1 X M}\left(R_{1}+R_{2}+R_{3}\right)
$$

A diagrammatic representation of the region in the NucFil-016 filter where hydrogen will diffuse is shown in Fig. 2. The carbon filter element is capable of retaining particles larger than 0.3 micron. Even though the pore size of this filter is not specified by the manufacturer its value might very well be on the same order of magnitude as the size of the smallest particles that can be retained. Diffusivity of gas through a porous medium is reduced whenever the mean free path of the diffusing gas is of the same order of magnitude as the pore size of the medium (Cussler 1988).

For ideal gases, the mean free path $\lambda$ is given by

$$
\lambda=\frac{k_{B} T}{\sqrt{2 \pi} d^{2} P}
$$

where, $k_{B}$ is the Boltzman constant, and d is the molecular diameter (see Reid et al. 1987). For hydrogen at s.t.p. we have

$$
\lambda=\frac{\left(1.3805 \times 10^{-23} \text { Joules } / \mathrm{K}\right)(273 \mathrm{~K})}{\sqrt{2 \pi}\left(2.827 \times 10^{-10} \mathrm{~m}\right)^{2}\left(1013 \times 10^{5} \text { Newton } / \mathrm{m}^{2}\right)}=0.2 \text { micron }
$$

Therefore, the mean free path that is of the same order of magnitude as the smallest particles that can be filtered. Under this situation, the diffusivity through the filter will likely be reduced. The factor by which the diffusivity is reduced is referred to as the tortuosity $\tau$ of the medium (which depends on pore size and the microstructure of the filter). The effective diffusivity through a porous medium is often written as

$$
D_{\text {eff }}=\frac{D}{\tau}
$$

It has been suggested that typical values of tortuosity average about 3 (Cussler 1988). I will assume this value in the calculation of the filter diffusive resistance. Therefore, an estimate of the hydrogen diffusivity through the carbon filter $D_{c f}$ is 


$$
D_{c f}=\frac{0.62 \mathrm{~cm}^{2} / \mathrm{sec}}{3}=0.21 \mathrm{~cm}^{2} / \mathrm{sec}
$$

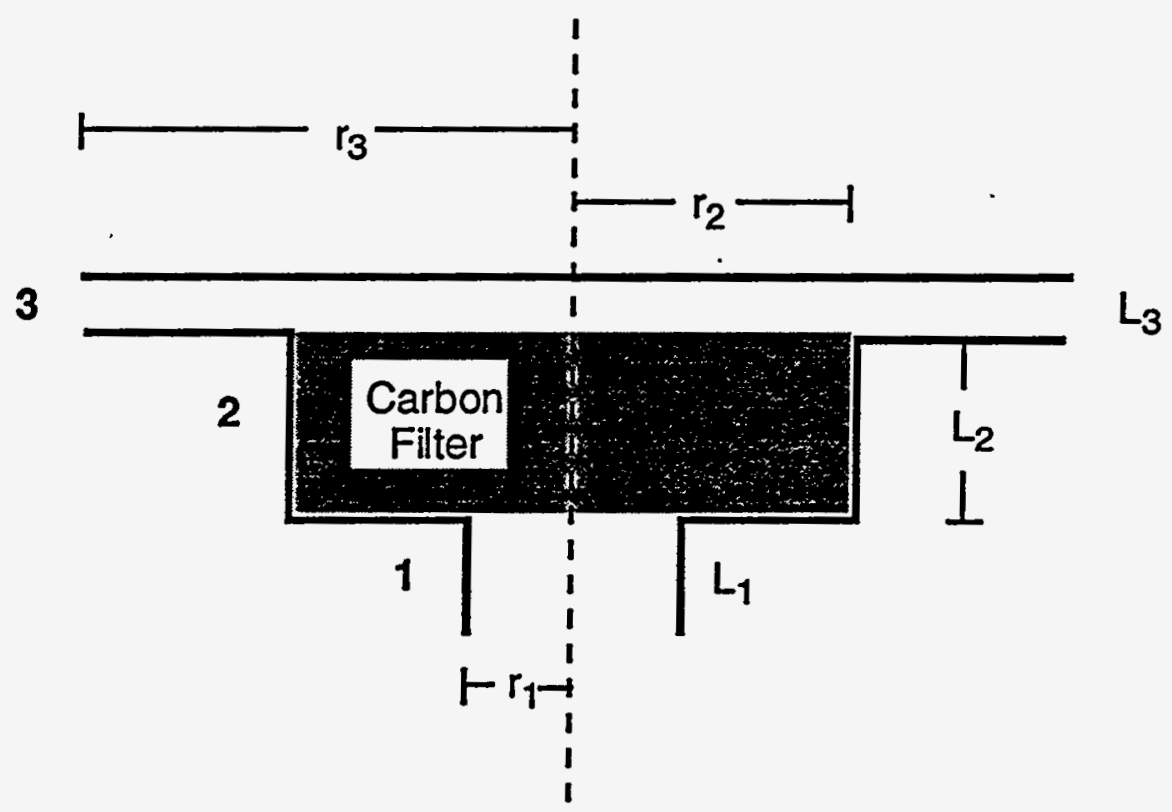

Figure 2. Section of NucFil 016 along its axis of symmetry.

Dimensions for Fig. 2

$$
\begin{aligned}
& L_{1}=1.016 \mathrm{~cm}, \quad L_{2}=1.778 \mathrm{~cm}, \quad L_{3}=0.191 \mathrm{~cm} \text {, } \\
& r_{1}=1.27 \mathrm{~cm}, \quad r_{2}=2.54 \mathrm{~cm}, \quad r_{3}=3.72 \mathrm{~cm} \text {. }
\end{aligned}
$$

The total resistance to diffusion of hydrogen in air through the NucFil-016 is calculated by adding the resistances of planar sections 1 and 2, and the radial section 3 (see. Fig. 2).

$$
R_{N F T-016}=\frac{1}{\pi D}\left[\frac{L_{1}}{r_{1}^{2}}+\frac{\tau L_{2}}{r_{2}^{2}}+\frac{\ln \left(\frac{r_{3}}{r_{2}}\right)}{2 L_{3}}\right]=1.26 \mathrm{sec} / \mathrm{cm}^{3}
$$

The vent pipe in the IXM is $50.8 \mathrm{~cm}$ (20 inch) long and has an internal diameter of $1.58 \mathrm{~cm}(0.622$ inch). Its resistance to diffusion is

$$
R_{\text {vent }}=\frac{50.8 \mathrm{~cm}}{(\pi / 4)(1.58 \mathrm{~cm})^{2}\left(0.62 \mathrm{~cm}^{2} / \mathrm{sec}\right)}=41.79 \mathrm{sec} / \mathrm{cm}^{3}
$$


The pipe elements labeled with subindex 1 in Fig. 1 are $15.88 \mathrm{~cm}$ (6.25 inch) long with an internal diameter of $4.09 \mathrm{~cm}$ (11/2 inch Schedule 40 pipe). Their resistance is

$$
R_{1}=\frac{15.88 \mathrm{~cm}}{(\pi / 4)(4.09 \mathrm{~cm})^{2}\left(0.62 \mathrm{~cm}^{2} / \mathrm{sec}\right)}=195 \mathrm{sec} / \mathrm{cm}^{3}
$$

The pipe elements labeled with subindex 2 in Fig. 1 are $40.64 \mathrm{~cm}$ (16 inch) long with an internal diameter of $7.79 \mathrm{~cm}$ ( 3 inch Schedule 40 pipe). Their resistance is

$$
R_{2}=\frac{40.64 \mathrm{~cm}}{(\pi / 4)(7.79 \mathrm{~cm})^{2}\left(0.62 \mathrm{~cm}^{2} / \mathrm{sec}\right)}=1.38 \mathrm{sec} / \mathrm{cm}^{3}
$$

The resistance to element 3 in Fig. 1 is

$$
R_{3}=R_{\text {vent }}+R_{\text {NFT-016 }}=43.05 \mathrm{sec} / \mathrm{cm}^{3}
$$

If we assume that in the IXM hydrogen is produced at the rate of $10^{-3} \mathrm{liter} / \mathrm{hr}$, then the maximum hydrogen and oxygen mole fractions are

$$
\begin{aligned}
x_{1}=\frac{N_{I X M}}{C}\left(R_{1}+R_{2}+R_{3}\right) & =\left(10^{-3} \text { liter } / \mathrm{hr}\right)\left(46.38 \mathrm{sec} / \mathrm{cm}^{3}\right) \times \frac{10^{3} \mathrm{~cm}^{3} \mathrm{hr}}{3600 \text { liter sec }}=0.013 \\
x_{2} & =\frac{1}{2} x_{1} \frac{D_{1}}{D_{2}}=\frac{1}{2}(0.013) \frac{0.62}{0.178}=0.023
\end{aligned}
$$

Therefore, in the absence of oxygen depletion, the maximum concentration of gases in the IXM for this example are: $1.3 \%$ hydrogen, $2.3 \%$ excess oxygen, and $96.4 \%$ air. In terms of elemental components we have: $1.3 \%$ hydrogen, $22.5 \%$ oxygen, and $76.2 \%$ nitrogen. Let us allow for depletion of oxygen and a production of another component which could be in the worst case a flammable component. Let us assume that oxygen can vary by $2.3 \%$ from the original content of oxygen in air. It is unlikely that the content of oxygen can diminish to less than $18.7 \%$ because the rate of production of oxygen by radiolysis is much greater than its depletion by aliphatic fragment oxidation. In addition, diffusion of oxygen from the atmosphere to the inside of the IXM will tend to occur whenever the concentration of oxygen diminishes. In the worst case, as the oxygen concentration drops the concentration of the flammable gas (carboxylic acid or alcohol vapor) increases.

Under the assumptions made above, whether or not a mixture inside the IXM is flammable or not can be determined from the flammability diagram for hydrogen- 
oxygen-nitrogen mixtures. This is because we are assuming that whatever product from the oxidation reaction (alcohol or carboxylic acid) is conservatively assumed to be as flammable as hydrogen. It should be noted that in the best case, the final product of the oxidation of the aliphatic fragment could be carbon dioxide.

The range of worst-case flammable mixtures obtained by assuming a depletion of oxygen in the range $17.8<\mathrm{O}_{2}<22.5$, and the production of a flammable gas (assumed to be as flammable as hydrogen) in the range $0<F . G$. $<4.7$ (A to B) is plotted in the flammability diagram for hydrogen (Jones 1929) shown in Fig. 3 . The resulting flammable mixture of hydrogen and the carboxylic acid in vapor form is assumed to be as flammable as hydrogen.

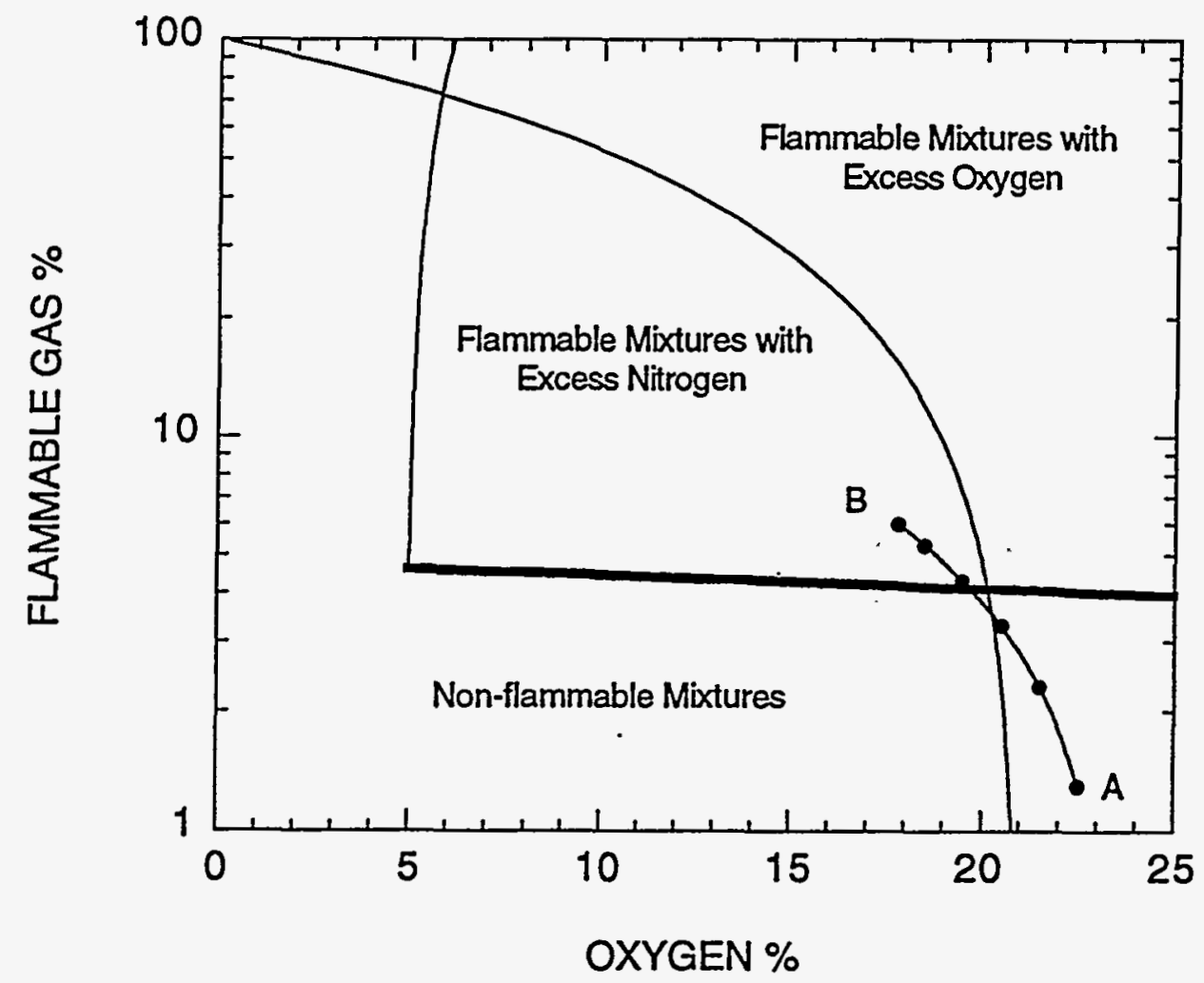

Figure 3. Worst-case Scenarios for Flammable Mixtures in an IXM.

\section{CONCLUSION}

Within an IXM, the oxygen concentration would have to drop below normal air levels and there would have to be an additional $2.8 \%$ of flammable gas (other than hydrogen) to render the mixture explosive. These conservative calculations showed that even under the assumption of worst case situations, the flammability of the hypothetical mixture is marginal. In reality, only a small fraction (unknown) of the liquid phase carboxylic acid will evaporate. Most of the oxidation products will be adhered in liquid form to the resin thus not entering into the flammable gaseous mixture. 


\section{APPENDIX}

The experimental data in this appendix for the flammability of hydrogen and other gases in mixtures of oxygen and nitrogen was reported by Jones (1929). The data is presented in table as well as graphical form.

TABLE 1.-Extinction of hylrogen flames by niliogen

\begin{tabular}{|c|c|c|c|c|c|c|c|}
\hline \multirow{2}{*}{\multicolumn{2}{|c|}{$\underset{\text { per cont }}{\text { Test mixturt, }}$}} & \multicolumn{4}{|c|}{$\begin{array}{l}\text { Compositton of linit mirture } \\
\text { after addition of air, por cont } \\
\text { by volume }\end{array}$} & \multirow{2}{*}{\multicolumn{2}{|c|}{$\begin{array}{c}\text { Infnmmable } \\
\text { limits of test } \\
\text { mlxture, per } \\
\text { cont by rolume, } \\
\mathrm{H}_{2}+\mathrm{N}_{2}\end{array}$}} \\
\hline & & \multicolumn{2}{|c|}{ Alr } & \multicolumn{2}{|c|}{ Test mlxturo } & & \\
\hline $\mathrm{II}_{2}$ & $\mathrm{Ni}_{2}$ & $\mathrm{O}_{2}$ & $\mathrm{~N}_{2}$ & $\pi_{2}$ & $\mathrm{~N}_{2}$ & Lower & Upper \\
\hline $\begin{array}{r}100.0 \\
70.6 \\
39.5 \\
20.1 \\
15.2\end{array}$ & $\begin{array}{l}0.0 \\
29.4 \\
00.5 \\
70.9 \\
84.8\end{array}$ & $\begin{array}{l}5.9 \\
6.8 \\
6.3 \\
6.1 \\
6.1\end{array}$ & $\begin{array}{l}22.1 \\
21.4 \\
10.8 . \\
14.2 \\
10.3\end{array}$ & $\begin{array}{l}72.0 \\
61.0 \\
20.8 \\
15.2 \\
11.5\end{array}$ & $\begin{array}{l}0.0 \\
21.5 \\
45.3 \\
\infty 0.5 \\
04.1\end{array}$ & & $\begin{array}{l}72.0 \\
73.0 \\
71.9 \\
75.7 \\
75.0\end{array}$ \\
\hline $\begin{array}{l}0.7 \\
0.4 \\
8.9 \\
8.2 \\
7.9\end{array}$ & $\begin{array}{l}60.3 \\
60.0 \\
01.1 \\
91.8 \\
92.1\end{array}$ & $\begin{array}{l}1.0 \\
1.9 \\
4.9 \\
6.1 \\
5.2\end{array}$ & $\begin{array}{l}18.5 \\
18.0 \\
18.7 \\
19.2 \\
19.7\end{array}$ & $\begin{array}{l}7.1 \\
7.2 \\
0.8 \\
0.2 \\
0.0\end{array}$ & $\begin{array}{l}60.2 \\
01.3 \\
60.6 \\
60.5 \\
69.1\end{array}$ & 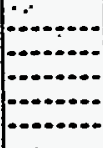 & $\begin{array}{l}70.6 \\
70.5 \\
78.4 \\
75.7 \\
75.1\end{array}$ \\
\hline $\begin{array}{r}\dot{7.2} \\
8.7 \\
83.3 \\
100.0\end{array}$ & $\begin{array}{r}92.8 \\
41.3 \\
46.7 \\
.0\end{array}$ & $\begin{array}{r}4.9 \\
8.1 \\
19.3 \\
20.1\end{array}$ & $\begin{array}{l}18.7 \\
10.8 \\
73.0 \\
75.8\end{array}$ & $\begin{array}{l}8.8 \\
4.3 \\
1.1 \\
1.0\end{array}$ & $\begin{array}{r}70.9 \\
71.1 \\
3.6 \\
.0\end{array}$ & \begin{tabular}{l}
0 \\
\hdashline 3.3 \\
7.7 \\
4.0
\end{tabular} & \begin{tabular}{c}
76.4 \\
75.4 \\
\hdashline$\cdots$ \\
\hdashline$\cdots$
\end{tabular} \\
\hline
\end{tabular}

\begin{tabular}{|c|c|c|c|c|c|c|c|}
\hline \multicolumn{2}{|c|}{ 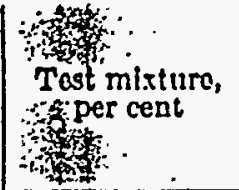 } & \multicolumn{4}{|c|}{$\begin{array}{l}\text { Composition of limit mixture } \\
\text { Rfter ndddition of air. per cent } \\
\text { by volume }\end{array}$} & \multicolumn{2}{|c|}{$\begin{array}{l}\text { Infnmmable } \\
\text { limits of tost } \\
\text { mixture, per } \\
\text { cent by yolume, } \\
\text { I1 + } \mathrm{CO}_{2}\end{array}$} \\
\hline \multirow{2}{*}{ 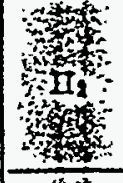 } & \multirow{2}{*}{$\mathrm{CO}_{2}$} & \multicolumn{2}{|c|}{ Air } & \multicolumn{2}{|c|}{ Test mixture } & \multirow{2}{*}{$\begin{array}{l}\therefore \\
\text { Lomer } \\
\vdots\end{array}$} & \multirow{2}{*}{ Upper } \\
\hline & & $\mathrm{O}_{3}$ & $\mathrm{Ni}$ & $\mathrm{El}_{2}$ & $\mathrm{CO}_{2}$ & & \\
\hline 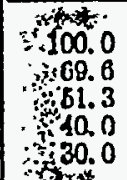 & $\begin{array}{r}0.0 \\
30.4 \\
48.7 \\
00.0 \\
70.0\end{array}$ & $\begin{array}{l}5.0 \\
0.2 \\
0.13 \\
0.9 \\
7.0\end{array}$ & $\begin{array}{l}22.1 \\
23.5 \\
24.8 \\
24.1 \\
21.7\end{array}$ & $\begin{array}{l}72.0 \\
48.9 \\
35.2 \\
26.3 \\
10.0\end{array}$ & $\begin{array}{r}0.0 \\
21.4 \\
33.4 \\
40.2 \\
40.4\end{array}$ & & $\begin{array}{l}\frac{72.0}{70.3} \\
7 \times .6 \\
67.0 \\
62.3\end{array}$ \\
\hline 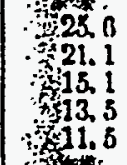 & $\begin{array}{l}74.4 \\
7.40 \\
\$ 4.0 \\
84.5 \\
88.5\end{array}$ & $\begin{array}{l}7.1 \\
7.3 \\
i .3 \\
i .0 \\
7.6\end{array}$ & $\begin{array}{l}2 \pi .0 \\
2 \pi .7 \\
2 \pi .8 \\
3 \times .7 \\
2 \pi .0\end{array}$ & $\begin{array}{r}16.9 \\
13.7 \\
9.8 \\
8.0 \\
7.3\end{array}$ & $\begin{array}{l}10.1 \\
51.3 \\
55.1 \\
55.1 \\
30.2\end{array}$ & $\mid$\begin{tabular}{l}
$\cdots$ \\
$\cdots$ \\
\hdashline- \\
$\cdots$
\end{tabular} & $\begin{array}{l}60.0 \\
65.0 \\
\text { GH. } \\
63.9 \\
63.7 \\
63.5\end{array}$ \\
\hline 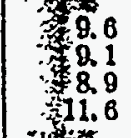 & $\begin{array}{l}\text { M..4 } \\
\text { xi. } \\
\text { Mi.. } \\
\text { \&.. }\end{array}$ & $\begin{array}{r}7.8 \\
8.8 \\
8.4 \\
11.7\end{array}$ & $\begin{array}{r}29.7 \\
31.3 \\
32.0 \\
41.4\end{array}$ & $\begin{array}{l}0.0 \\
5.5 \\
5.3 \\
5.1\end{array}$ & $\begin{array}{l}5 \times .5 \\
5.4 .9 \\
5,1.3 \\
38.8\end{array}$ & 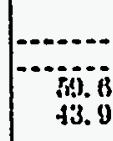 & $\begin{array}{l}62.5 \\
6(x) .1 \\
613.6\end{array}$ \\
\hline 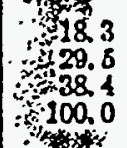 & $\begin{array}{r}81.7 \\
70.5 \\
01.0 \\
.0\end{array}$ & $\begin{array}{l}16.1 \\
17.9 \\
18.7 \\
20.1\end{array}$ & $\begin{array}{l}61.0 \\
60.0 \\
70.6 \\
75.9\end{array}$ & $\begin{array}{l}4.2 \\
4.2 \\
4.1 \\
1.0\end{array}$ & $\begin{array}{r}18.7 \\
10: 0 \\
0.0 \\
.0\end{array}$ & $\begin{array}{r}72.9 \\
14.2 \\
10.7 \\
4.0\end{array}$ & $\cdots$ \\
\hline
\end{tabular}


TABLE 8. - Limits of inflammabilily of hydrogen and nilrogen mixtures

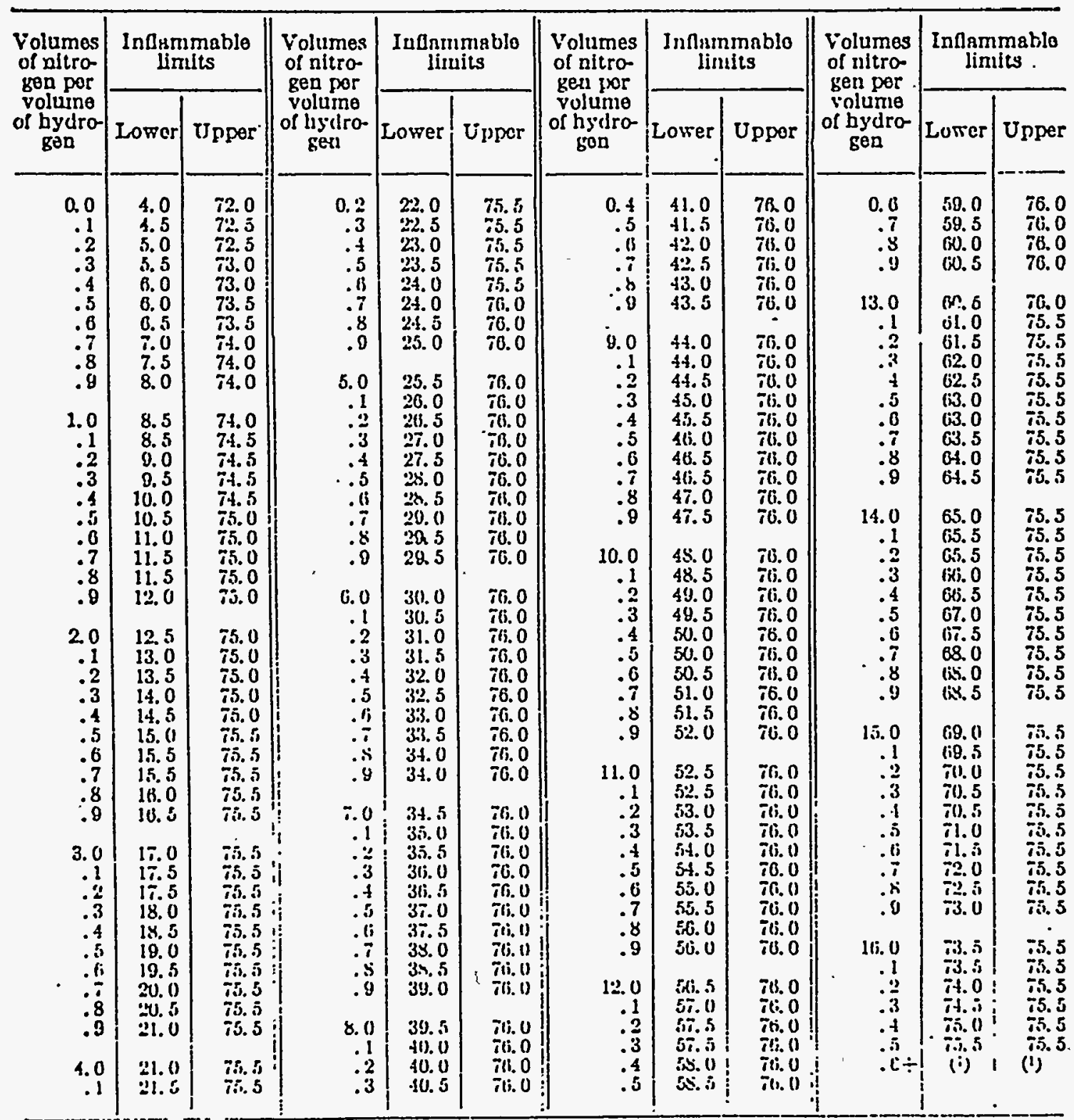

1 Xoniullummuble. 
TABLE 9.-Limits of inflammability of hydrogen and carbon dioxide mixtures

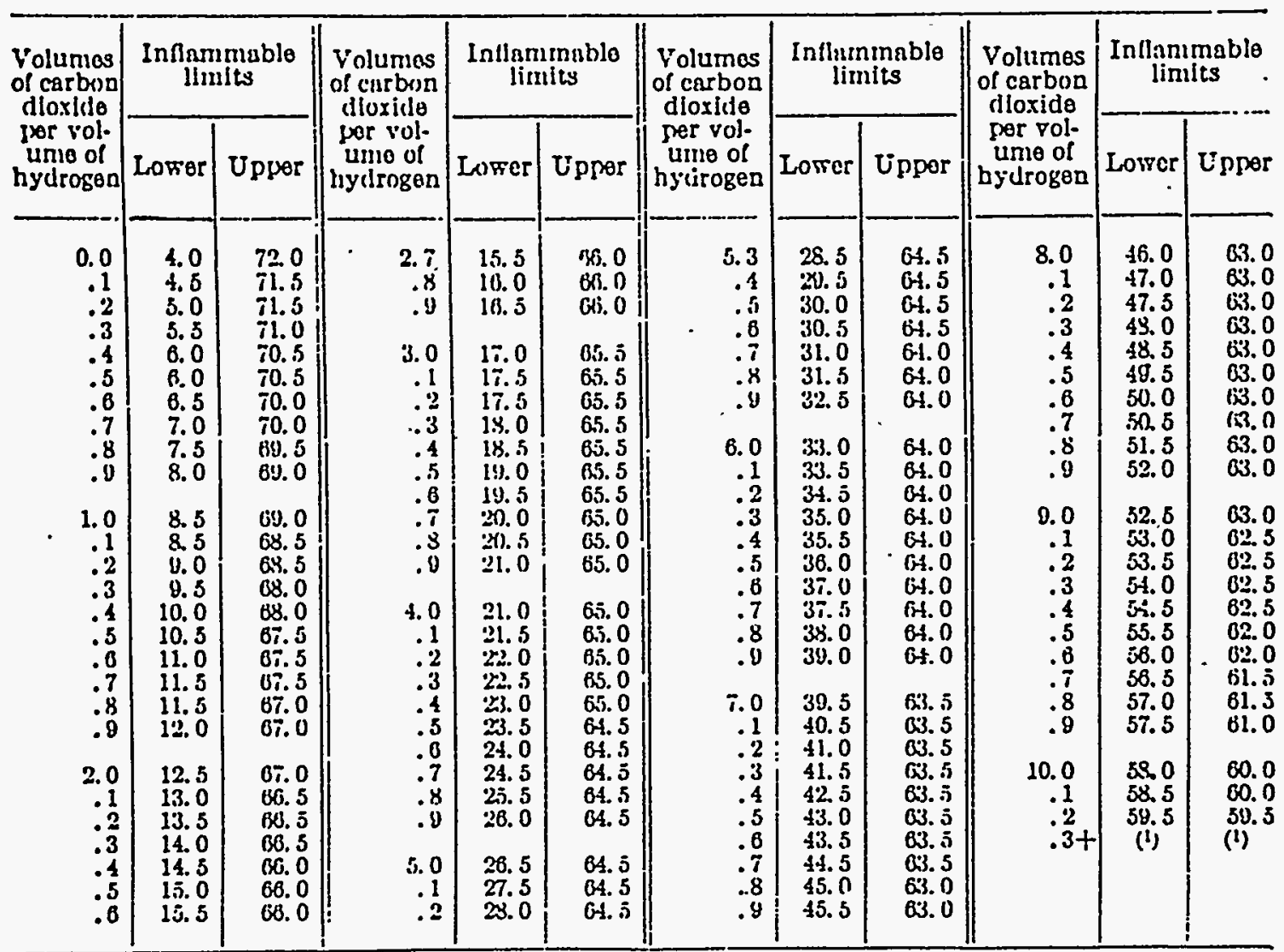

I Nonincanumablo.

TABLE 10.-Limils of inflammability of carbon munoxide and milrogen miixtures

\begin{tabular}{|c|c|c|c|c|c|}
\hline \multirow{2}{*}{$\begin{array}{l}\text { Volumiss } \\
\text { of nitro- } \\
\text { kil pert } \\
\text { volumis } \\
\text { of car- } \\
\text { bon mon- } \\
\text { oxide }\end{array}$} & \multicolumn{2}{|c|}{$\underset{\substack{\text { Inflammanable } \\
\text { limits }}}{ }$} & \multirow{2}{*}{$\begin{array}{l}\text { Volumrs } \\
\text { of nitro- } \\
\text { gen per } \\
\text { volume } \\
\text { of car. } \\
\text { bon.minn- } \\
\text { oxille }\end{array}$} & \multicolumn{2}{|c|}{$\underset{\substack{\text { Inflammits } \\
\text { limble }}}{ }$} \\
\hline & Inwer & $c_{\text {Pupre }}$ & & Lower & Upper \\
\hline $\begin{array}{l}0.0 \\
.1 \\
.2 \\
.3 \\
.4 \\
.5 \\
.10 \\
.7 \\
.8 \\
.9\end{array}$ & $\begin{array}{l}13.0 \\
11.5 \\
115.0 \\
17.0 \\
18.5 \\
20.0 \\
21.0 \\
22.5 \\
24.0 \\
25.5\end{array}$ & 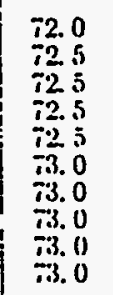 & $\begin{array}{l}20 \\
.1 \\
.2 \\
.3 \\
.4 \\
.5 \\
.5 \\
.8 \\
.8 \\
.0\end{array}$ & $\begin{array}{l}40.5 \\
+2.0 \\
43.0 \\
.14 .5 \\
+16.0 \\
17.5 \\
18.5 \\
1.0 \\
50.0 \\
53.5 \\
53.0\end{array}$ & $\begin{array}{l}73.0 \\
73.0 \\
73.0 \\
73.0 \\
73.0 \\
73.0 \\
73.0 \\
73.0 \\
73.0 \\
73.0 \\
73.0 \\
73.0\end{array}$ \\
\hline $\begin{array}{r}1.0 \\
.1 \\
.2 \\
.3 \\
.1 \\
.3 \\
.6 \\
.7 \\
.8 \\
.9\end{array}$ & $\begin{array}{l}27.0 \\
38.0 \\
23.5 \\
31.0 \\
332.5 \\
33.5 \\
35.0 \\
30.5 \\
37.5 \\
34.0\end{array}$ & 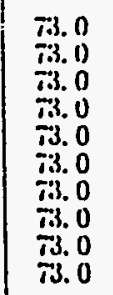 & $\begin{array}{l}3.0 \\
.1 \\
.2 \\
.3 \\
.4 \\
.3 \\
.6 \\
.8 \\
.8 \\
.0\end{array}$ & 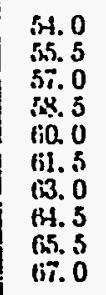 & $\begin{array}{l}73.0 \\
73.0 \\
73.0 \\
73.0 \\
73.0 \\
725 \\
725 \\
72.5 \\
72.5 \\
72.03 \\
720\end{array}$ \\
\hline & & & $\begin{array}{l}4.0 \\
.10 \\
.2+\end{array}$ & $\begin{array}{c}\text { ax. } 5^{\circ} \\
\text { ill. } \\
\text { il. } \\
\text { (i) }\end{array}$ & $\begin{array}{c}720 \\
71.0 \\
3110 \\
\text { (i) }\end{array}$ \\
\hline
\end{tabular}

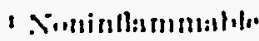




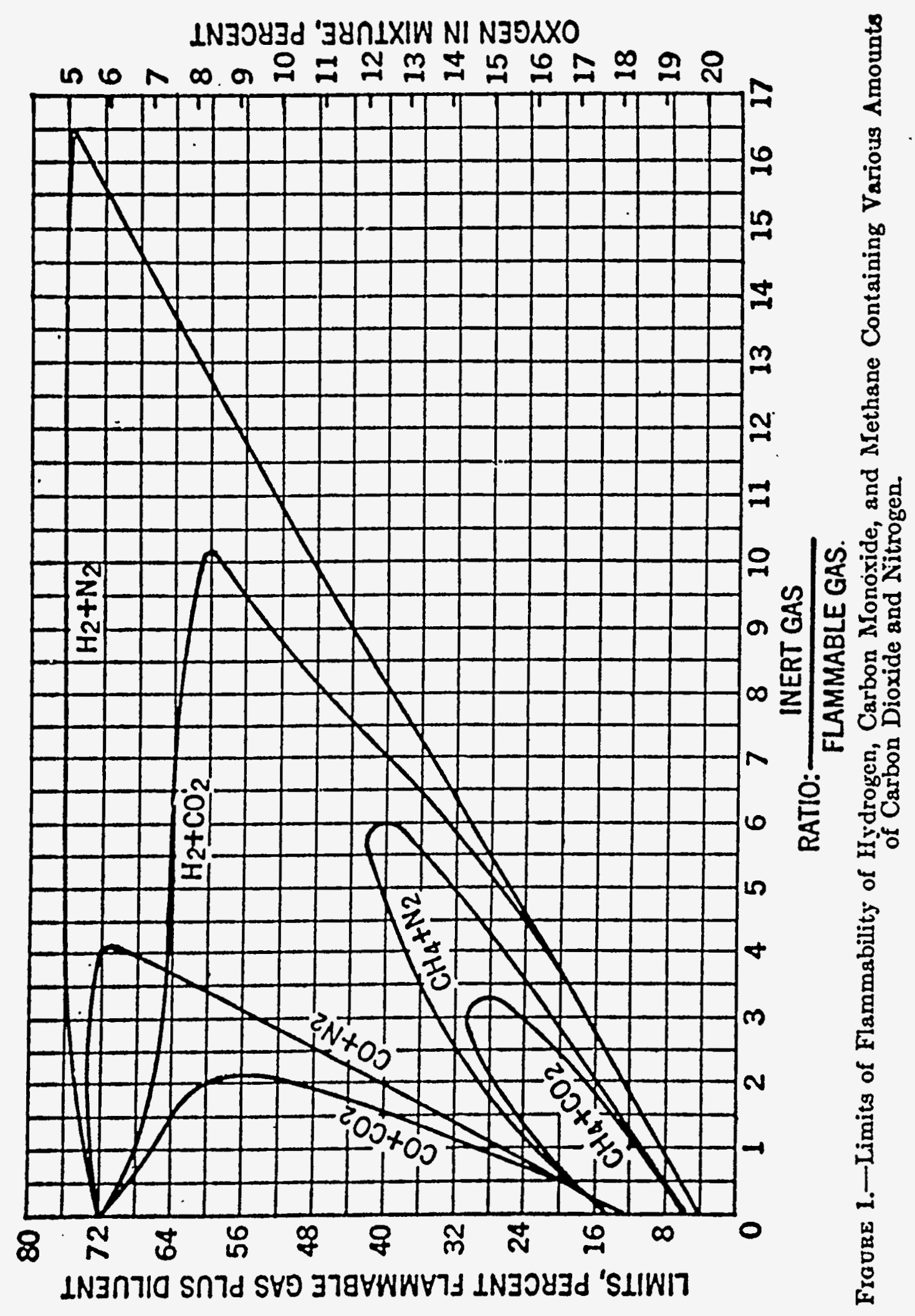




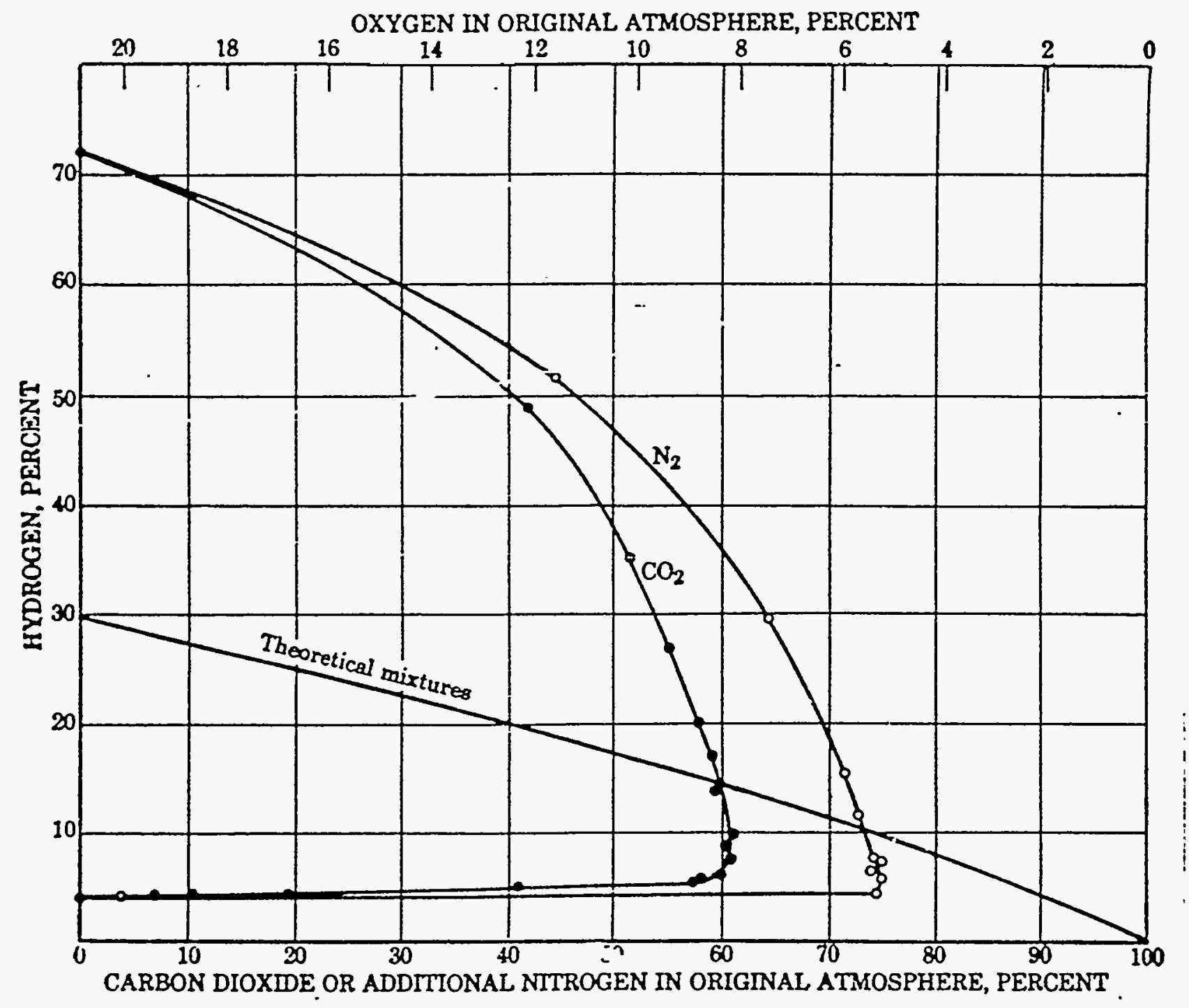

Frrtre 7.-Limits of Flammalitity of Hydrogeil in Air and Carbon Dioxide or Nitrogen. 


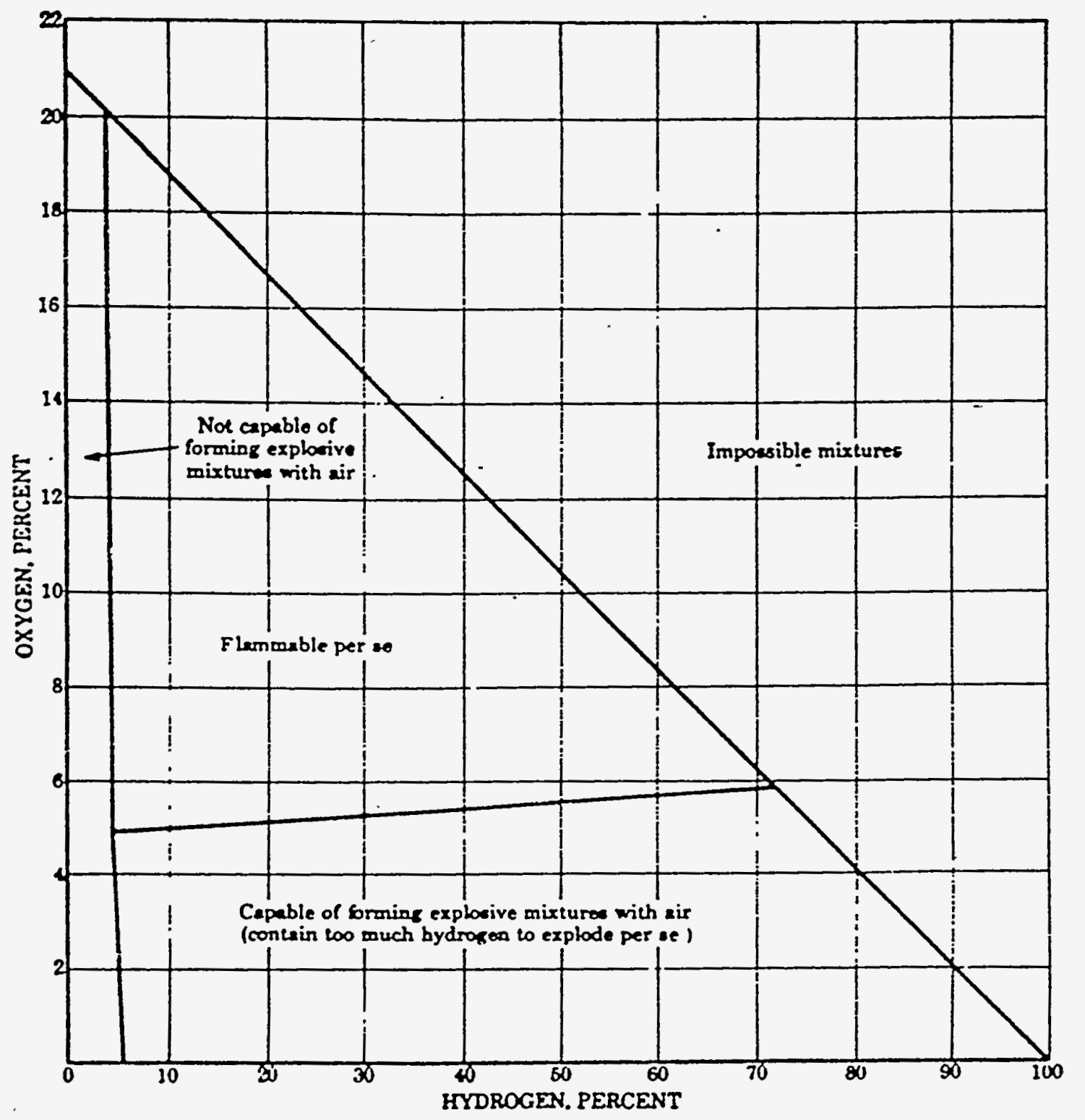

Relation Between Composition and Flammability of Mixtures of Hydrogen, Oxygen, and Nitrogen 
Date August 25, 1995 •

Jim Bates

Mike Urié

To Lucia Li1jegren

From Padmanabhan Melethit

Subject

Oxygen depletion in IXM

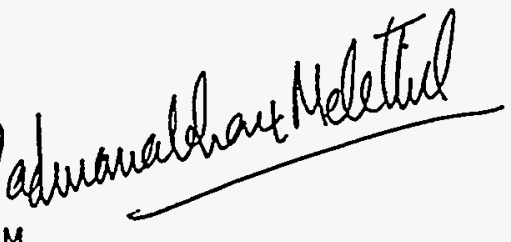

File/LB

This memorandum addresses the modeling of oxygen depletion in K Basin IXMs.

Oxygen depletion is caused by oxidation of resin, yielding weak acid

functionality such as carboxylates ( $\mathrm{RCOOH})$ or phenolics (ROH). Oxidation is promoted by oxygen or other oxidizing agents such as nitrate and hypochlorite, by temperature, and by radiation.

The resins in use at $K$ Basin are polystyrene-divinylbenzene (PS-DVB) copolymers, sulfonated for cation exchange and with quaternary ammonium groups for anion exchange, e.g., Purolite NRW-37. Though experimental measurements are not available for the modeling of oxygen depletion in this resin, data on other resins are available.

Contributions to oxidation, due to radiation and thermal effects are estimated from values in the published literature.

\section{Contributions from Radiation}

The radiation level at centerline, for $K$ Basin columns, has been estimated to be $500 \mathrm{R} / \mathrm{Hr}$, and storage for 5 years results in an integrated dose of $2 \times 10^{7}$ rad (Marusich, 1994). However, the values for the radiation source terms should apparently be raised by a factor of two, based on actual data (Hawkes, 1994). This increase should provide a conservatively high estimate for column radiation levels.

Weak acid capacity increase in wet sulfonated PS-DVB resins, as a function of dose, has been found to be about $0.1 \mathrm{meq} / \mathrm{g}$ for a dose of $10^{8} \mathrm{rad}$ (Kubota, 1978).

Based on these inputs, we calculate the oxidation of resin due to radiation as

$$
0.8 \times 10^{7}(\mathrm{rad} / \mathrm{yr}) \times 0.1 \text { (meq/g) } \times 10^{-8}(\mathrm{yr} / \mathrm{Rad})
$$

which is equal to $8 \mu \mathrm{eq}$ per gram of resin per year. . 
Though carboxylic acids use two atoms of oxygen to produce a carboxylate and phenolics use only one atom of oxygen, both oxidative steps may be considered to use two atoms of oxygen to eventually yield $\mathrm{CO}_{2}$. Then, one molecule of oxygen produces one "molecule" of acid.

Based on these assumptions, the radiation levels in the $K$ Basin columns are estimated to deplete $8 \times 10^{-6}$ moles $0_{2}$ per gram of resin per year or $9 \times 10^{-10}$ moles $\mathrm{O}_{2}$ per gram of resin per $\mathrm{hr}$.

\section{Contributions from thermal effects}

A recent PNL report (Brown, 1995) measured oxygen uptake by macrocycle and resorcinol-formaldehyde (R-F) resins. The data published for the $R-F$ resins, in contact with $1 \mathrm{M} \mathrm{NaOH}$ and under a $100 \% \mathrm{O}_{2}$ atmosphere, are used below to estimate the behavior of PS-DVB resins, e.g., NRW-37.

Based on earlier work (Kalwarf, 1977), sulfonated PS-DVB resins are expected to be less radiolytically stable than sulfonated R-F resins. Commercial resins are not understood well enough to suggest that trends in their radiolytic stability would be followed by their thermal stability. Assuming that PS-DVB resins are as stable as R-F resins, the thermally induced rate of oxygen uptake of the former is expected to be

Fraction of $\mathrm{O}_{2}$ in air $x$ 0xygen uptake by $\mathrm{R}-\mathrm{F}$ resin

$$
=0.2 \times 0.34 \times 10^{-3}=7 \times 10^{-5} 0_{2} \text { per gram of resin per hour) }
$$

The uptake of oxygen has been assumed to be first order, or linear in oxygen concentration (i.e., $d\left[\mathrm{O}_{2}\right] / \mathrm{dt}=\mathrm{k}\left[\mathrm{O}_{2}\right]$ ). This has been demonstrated for radiolytic oxidation of ion exchange media (Swyler, 1983).

\section{Summary}

The total oxygen uptake of organic resins is modeled as the sum of two contributions, thermal and radiolytic. For the columns at $K$ basin, the thermal oxidative contribution is expected to be the significant one.

$$
\begin{aligned}
& \text { Total 0xygen uptake }=\text { Uptake (rad) + Uptake (therm) } \\
& \text { (moles } \mathrm{O}_{2} \mathrm{~g}^{-1} \mathrm{hr}^{-1} \text { ) } \\
& =9 \times 10^{-10}+7 \times 10^{-5} \\
& -7 \times 10^{-5}
\end{aligned}
$$


Lucia Li7jegren

August 25, 1995

Page 3

This estimate is expected to fall within one order of magnitude of the true value.

\section{REFERENCES}

Brown, G. N., et. a1. 1995. Chemical and Radiation Stability of SuperLig 644, Resorcinol-Formaldehyde and Cs-100 Cesium Ion Exchange Materials. PNLXXXXX (in press).

Hawkes, E. C., and Prichard, A. W. 1994. Radiation Source Terms in the K-E Basin Ion Exchange Columns. PNL-IX-IR-0014.

Kalwarf, D. R. 1977. Safety Evaluation of Cation-Exchange Resins. BNWL2391/UC-10.

Kubota, M., et. a1. 1978. Radiation Stability of Macro-Porous and Ge7-Type Cation Exchangers. J. Radioana7. Chem. : Vol. 45, pp. 73-89.

Marusich, R. 1994. Hydrogen in K-Basin Ion Exchange Columns (Draft), WHC memo dated October 7, 1994 .

Swyler, K. J., et. al. 1983. Irradiation Effects on the Storage and Disposal of Radwaste Containing Organic Ion-Exchange Media. NUREG/CR-3383. 
September 14, 1995

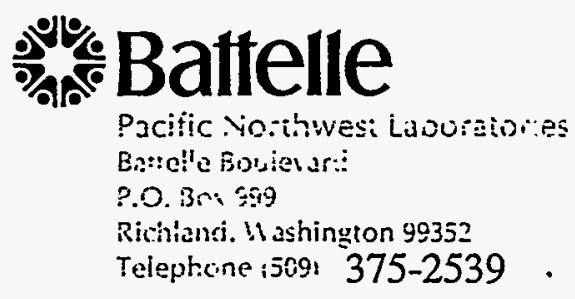

Cherri Defigh-Price

Restart \& Special Projects

K-Basin

Westinghouse Hanford Company

Richland, WA 99352

Dear Ms. Defigh-Price

I am submitting a document entitled "Hydrogen and Oxygen Concentrations in IXC's" by LM Liljegren (traceable by the project assigned number of PNL-IX-IR-0019). This work was performed under WO ED5322 and the associated Statement of Work as described in the letter from WHC's TB Veneziano to PNL's PJ Turner, dated February 3, 1995.

The major conclusion resulting from the analysis is that intact IXC's present no flammability hazard because the oxygen lever is below the flammability limit for hydrogen-oxygen combustion. All intact IXC's can be safely moved because the oxygen mole fraction is below $0.5 \%$, which is safely below the flammability limit of $5 \%$ oxygen for hydrogenoxygen mixtures.

If you have any questions, please-feel free to contact Lucia Liljegren at 375-2353.

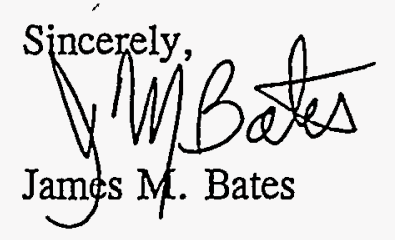

$\mathrm{JMB} / \mathrm{kr}$

Enclosure

cc: William Mills/WHC

Richard Lipinski /WHC

Dennis Kreid/PNL

Jim Bates/PNL

Lucia Liljegren/PNL

File/LB 
Title: Hydrogen and Oxygen Concentrations in IXC's

Document Number: __ PNL-IX-IR-0019
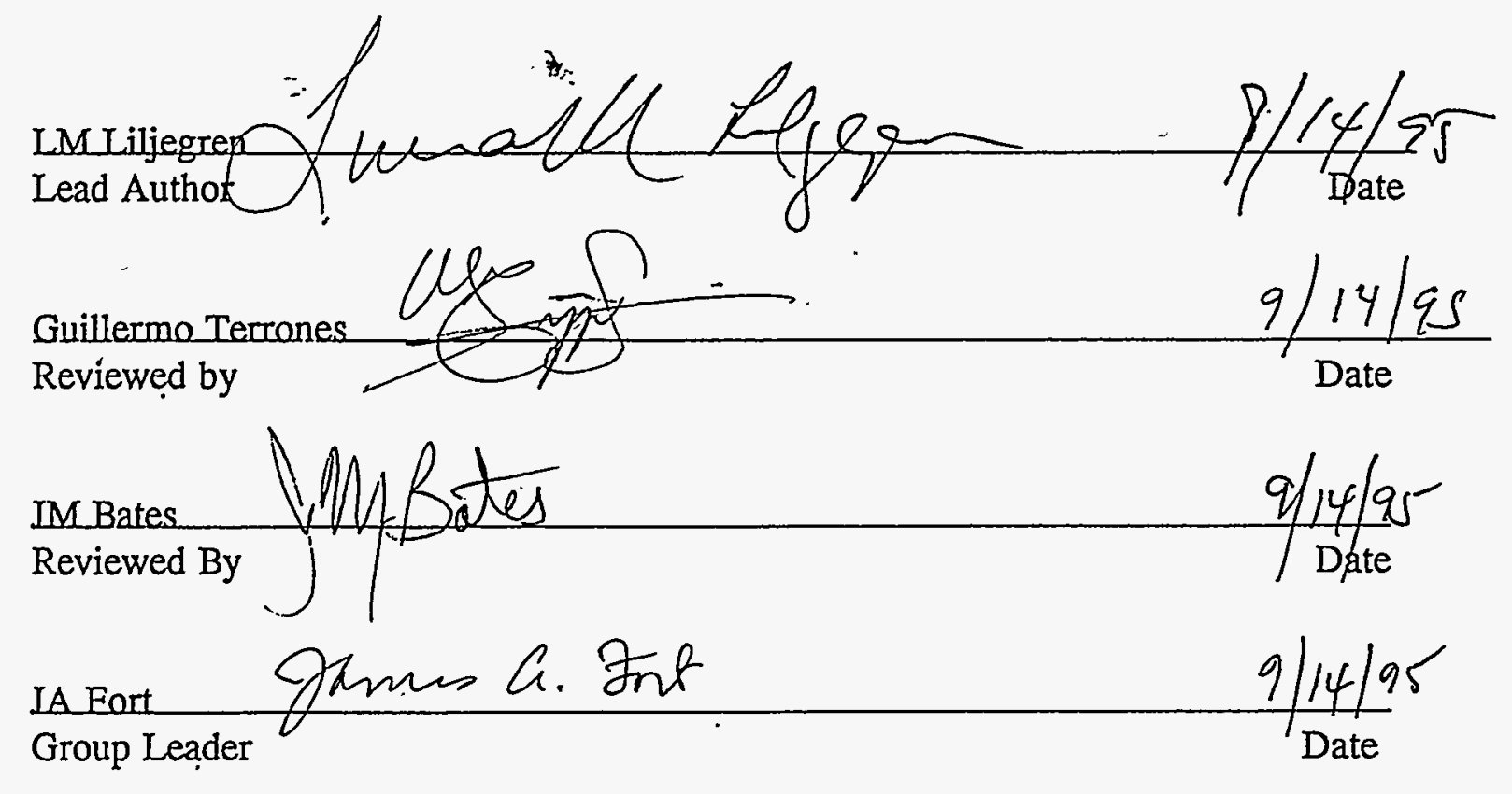

$\underset{\text { DKanager, HTSP . Peide }}{9 / 14 / 55}$ 
PNL-IX-IR-0019

Hydrogen and Oxygen Concentrations in IXC's

Lucia M. Liljegren

September 13, 1995

Pacific Northwest Laboratory

. Richland WA 99352 
To:

Bill Mills

From:

Subject: $\quad$ Flammability of gas contained in IXCs.

Date: $\quad$ September 12, 1995

Hydrogen and Oxygen concentrations in IXC's

\subsection{SUMMARY}

This calculation was performed to determine whether the gas contained in IXC's can be flammable. Hydrogen and oxygen are the major reactive gases detected in IXM's. They are expected to represent the only reactive gases to present a significant hazard in either IXC's or IXM's.

The major conclusion is that intact IXC's present no flammability hazard because the oxygen level is below the flammability limit for hydrogen-oxygen combustion. This analysis does not discuss hydrogen concentration for the following reason.

It cannot be shown with certainty that the hydrogen concentration is below $4 \%$ in every IXC. IXC's placed on their sides with resin covering the NUCFIL may have elevated hydrogen concentrations. However, all intact IXC's can be safely moved because the oxygen mole fraction is below $0.5 \%$, which is below the flammability limit of $5 \%$ oxygen for hydrogenoxygen mixtures.

It can be shown that many individual IXC's have hydrogen concentrations below the hydrogen flammability limit. For example, all IXC's in Big Berthal have hydrogen concentrations well below the flammability limit.

The analysis required examining two geometric configuration to determined the oxygen and hydrogen levels. IXCs are stored in a number of possible orientations. From the point of view of transport, only two extreme cases need be considered. The first is the case where the NUCFIL filter on an IXC is entirely uncovered by resin. The second is the case where the NUCFIL filter is entirely covered by the resin.

If we compare the two cases we find the following general conclusions:

\begin{tabular}{|l|l|}
\hline NUCFIn covered & NUCFIL uncovered \\
\hline $\begin{array}{l}\text { Predicted hydrogen achieves the highest } \\
\text { possible level at steady state. }\end{array}$ & $\begin{array}{l}\text { This geometry. will have the lowest levels of } \\
\text { hydrogen. }\end{array}$ \\
\hline $\begin{array}{l}\text { Oxygen achieved lowest possible level for } \\
\text { any geometry. Can use uncovered NUCFU } \\
\text { results conservatively. The oxygen mole } \\
\text { fraction is less than 0.5\%, }\end{array}$ & $\begin{array}{l}\text { oxygen concentration achieves highest } \\
\text { possible level for any geometry } \\
\text { The steady state oxygen mole fraction is less } \\
\text { than 0.5 \%. All IXC's should be at steady } \\
\text { state with respect to oxygen concentrations. }\end{array}$ \\
\hline
\end{tabular}

${ }^{1}$ LM Liljegren, 1995, Estimate of Hydrogen Concentrations in Big Bertha and the IXC's Contained in the Vessel. PNL-IX-0016. 


\begin{tabular}{|l|l|}
\hline Conclusion \\
$\begin{array}{l}\text { IXC safe because the oxygen mole fraction } \\
\text { is less than } 0.5 \% . \text { This is less than the } \\
\text { flammability limit of } 5 \% \text { required for } \\
\text { hydrogen combustion. }\end{array}$ & $\begin{array}{l}\text { Conclusion } \\
\text { less than because oxygen mole fraction is } \\
\text { flammability limit of } 5 \% 2 \text { required for } \\
\text { hydrogen combustion. }\end{array}$ \\
\hline
\end{tabular}

Note that, hypothetically, the IXC's with hydrogen concentration above $4 \%$ could become flammable under the following circumstance. If the $\mathrm{IXC}$ were breached so that air entered, the oxygen level would rise. The hydrogen level would simultaneously fall. As a result, gas inside and near an IXC would temporarily be flammable. This scenario has not been evaluated. Caution should be exercised in moving IXCs to ensure that they are not damaged when moved.

\section{LIMITATIONS}

This analysis does not apply to IXC's that are damaged such that gas flows freely to the atmosphere. The hydrogen concentration in damaged IXC's will always be less than in intact IXC; oxygen concentrations will always be higher. However, predicting the level of hydrogen or oxygen requires specific knowledge about the type of damage, and so is not feasible.

Because the only reason hydrogen accumulates is that ventilation in the IXC's is relatively poor, it is likely that damaged IXC's will allow sufficient transport to dilute hydrogen below flammability limits.

\subsection{Full model}

Each IXC consists of a cylindrical unit which contains drained resin, which may be damp. The $\mathrm{XXC}$ is connected to the atmosphere through a NUCFIL filter. The filter allows some flow and molecular diffusion to the atmosphere. An idealized sketch of an IXC is illustrated in Figure 1; this sketch shows one unit connected to the atmosphere through one NUCFIL.

Under current storage conditions, it is-possible for IXCs to be oriented in any direction with respect to gravity. It is possible to show that the highest oxygen concentration occurs in the upright position when the NUCFI is not blocked. This is true because in this position two things occur:

1) oxygen transport into the open volume of the IXC occurs through the NUCFIL only and is not inhibited in any way by the resin. So, oxygen enters more rapidly in this configuration.

2) The resistance to transport into the resin prevents oxygen from traveling into the resin where it can be consumed. When the resin is upright; the distance oxygen must travel is largest. So, the minimum oxygen is consumed.

For the purposes of estimating the oxygen mole fraction, the geometry was assumed to be upright. This will over predict the oxygen mole fraction for all other geometries.

To develop the transient model, the internal components of the IXM are divided into regions 1 and 2. Region 1 consists of all the gas in the open volume. Region 2 consists of resin. It is assumed that most of the resin is dry, because it was drained initially and has been sitting at

\footnotetext{
${ }^{2}$ Terrones, G..T. Flammability Limits of Hydrogen in the IXM's. Memo to Bill Mills, July 10, 1995.
} 
elevated temperatures for some time. The issue of interstitial liquids is important when predicting hydrogen transport because the hydrogen is preferentially generated in wet regions. It does not have a large impact on oxygen depletion, which occurs in both dry and wet resins. So, the damp resins will not inhibit oxygen depletion significantly.

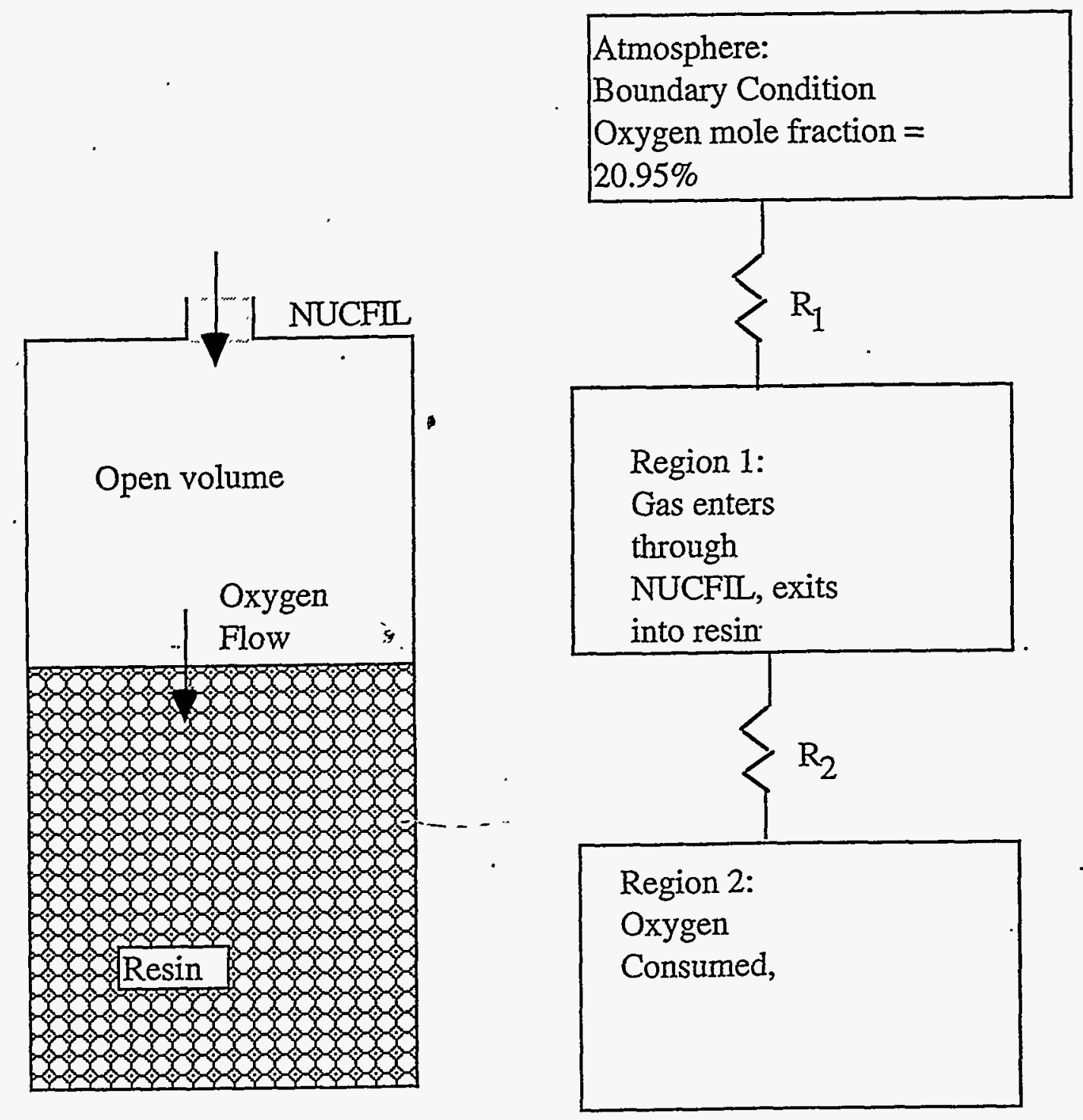

Figure 1. Idealized Model of an IXM.

A transient model based on this idealization was developed using the following assumptions: 
1) The major resistance to molecular diffusion and flow between the open volume in all IXC's and the atmosphere is the NUCFIL. This is equivalent to assuming that the gas composition is constant in the open volume of the IXC. This assumption is known to be correct based on estimates of the diffusivity in air compared to that in the NUCFIL.

3) The pressure in the vessel is approximately constant at all times. This is expected to be true because pressure induced flow occurs relatively freely through the NUCFIL.

4) All oxygen is depleted and all hydrogen is generated in the resin bed.

5) More gas is consumed than generated. This is based on the actual estimates of oxygen consumption and hydrogen generation; a self-consistency check is performed at the end of the calculation to this assumption. The assumption simplifies the mathematical equations, and has no real consequence.

6) Most of the resin is dry. So, the resistance to diffusion is unaffected by the presence of water.

The equations describing the transport of oxygen in regions 1 and 2 of the IXC are:

$$
\begin{aligned}
& V_{1} c \frac{d \chi_{10}}{d t}+\left[\frac{c}{R_{\text {Nucfilo }}}\left(\chi_{10}-\chi_{\infty o}\right)+\sum S_{j} \chi_{\infty}\right]-\left[c \frac{1}{R_{\text {Resin } O}}\left(\chi_{2 O}-\chi_{10}\right)+\sum S_{j} \chi_{1 O}\right]=0 \\
& V_{2} c \frac{d \chi_{2 O}}{d t}+\left[c \frac{1}{R_{R e \sin H}}\left(\chi_{2 O}-\chi_{10}\right)+\sum S_{j} \chi_{10}\right]=S_{o_{2}}
\end{aligned}
$$

where, $V_{1}$ is the volume of the open volume, that is region $1, V_{2}$ is the volume of gas in the pore space of the resin, $c$ is the molar concentration of gases in the IXM's, $\chi_{20}$ is the oxygen mole fraction in the resin bed, $\chi_{10}$ is the oxygen mole fraction in the open volume $\chi_{10}$ is the oxygen mole fraction in the atmosphere, $R_{\text {Resino } O}$ and $R_{\text {Nucfio }}$ are the diffusion resistance's. of the NUCFIL and the resin in units of time/volume and $S_{o_{2}}$ is the oxygen generation rate; a negative value corresponds to consumpintion.

The first term equation 1 represents the time rate of change of moles of oxygen in the open volume. The terms in the second bracket represent the rate at which moles of oxygen are enters from the atmosphere. The third term represents the rate at which moles of oxygen leaves the open volume and enters the resin bed, where it is consumed. It is assumed that the only gases generated or consumed in significant quantities are oxygen and hydrogen. This means that the sum of the generation rates is

$$
\sum S_{j}=S_{\mathrm{O}_{2}}+S_{H_{2}}
$$

where $S_{\mathrm{H}_{2}}$ is the hydrogen generation rate.

- Readers should note that the form of the equations assumes that the sum of the generation rates is negative; that is, it assumes that oxygen is consumed at a greater rate than hydrogen is generated. This cannot be known prior to solving the problem, and must be tested for self consistency at the end of the calculation. This was verified at after the steady-state oxygen concentrations were calculated. 
This system of equations was solved both for the transient case and the steady-state case. Several models were required to do this. These were:

1) A model for the oxygen consumption rate

2) A model for the hydrogen generation rate

3) A model for the resistance to diffusion into the resin bed.

4) A model for the resistance to diffusion of oxygen through a NUCFIL.

In the range studied, predictions were found to be affected most strongly by the model for resistance to diffusion of the resin bed. These models are described below.

1) The reaction leading to oxygen consumption was assumed have linear kinetics. So, the gas consumption rate was assumed to vary linearly with concentration of oxygen in the resin. Mathematically, this is equivalent to

$S_{\mathrm{O}_{2}}=S_{\mathrm{O}_{2}, 100 \%} x_{20}$

The gas consumption rate when the concentration of oxygen in the resin is $100 \%$ is assumed to be $S_{O_{2}, 100 \%}=-1.53 \times 10^{2}$ liters $/ \mathrm{hr}$. PK Melethil estimated that the lower bound on the oxygen consumption rate is $7 \times 10^{-2} \mathrm{mmole}_{2} / \mathrm{gram}$ resin $\mathrm{hr}$. If we assume that a resin bed has a void fraction of $40 \%$, the mass of $5 \mathrm{ft}^{3}$ of resin with an intrinsic density of $1.15 \times 10^{3}$ $\mathrm{kg} / \mathrm{m}^{3}$ is $97.7 \mathrm{~kg}$. This results in a consumption rate $S_{\mathrm{O}_{2}, 100 \%}=-1.53 \times 10^{2}$ liter @ stp $/ \mathrm{hr}$.

2) Because the oxygen consumption rates are larger than the hydrogen generation rates, and because hydrogen generation has only, an indirect effect on the oxygen transport, the predicted values of oxygen are affected only slightly by the assumed hydrogen generation rate. The value of $2.4 \times 10^{-3}$ liters @ stp/hr from IXC KW $60^{3}$ was selected for the purpose of calculating the oxygen level. So, $S_{H_{2}}=2.4 \times 10^{-3}$ liters @ stp/l was used for the purposes of calculating the oxygen level. The effect of hydrogen generation is to inhibit the flow of oxygen rich atmospheric gas into the IXC's. So, IXC's with lower hydrogen generation rates may have larger oxygen generation rates than predicted here. However, those DXC's will have hydrogen levels below the-LFL of hydrogen. IXC's with higher hydrogen generation rates will have lower oxygen generation rates. So, the effect of this assumption is conservative.

3) The resistance to diffusion through the resin bed was modeled as follows.

$$
R_{\text {Resin,o }} / c_{o}=\frac{H}{D_{\mathrm{O}_{2}, 0^{\circ} \mathrm{C}} A_{b e d} \phi_{b e d}} T
$$

where $H$ is the height of the resin bed, $D_{\mathrm{O}_{2}, 0^{\circ} \mathrm{C}}$ is the diffusivity of oxygen at STP, $A_{b e d}$ is the cross-sectional area of the bed, and $T$ is a tortuosity for the bed.

4) The internal diameter of the IXC is $18 "$. So, $5 \mathrm{ft}^{3}$ of resin for a bed height of $0.86 \mathrm{~m}$; use of the total height is conservative, as the average resistance is represented by $1 / 2$ the bed height. The diffusivity of oxygen in air is $0.178 \mathrm{~cm}^{2} / \mathrm{s}$ at $0 \mathrm{C}^{4}$. Values at elevated temperatures were not readily available. However, use of the value at $0 \mathrm{C}$ will tend to

${ }^{3}$ Estimate of Hydrogen Concentration in Big Bertha and the IXC's contained in the Vessel. LM Liljegren May $15,1995$.

${ }^{4}$ CRC Handbook of Chemistry and Physics 66th edition. 1985 Weast. CRC Press Boca Raton, Fla. 
overpredict the resistance, and the oxygen mole fraction because diffusivity increases with temperature. The area of a 18 " diameter cylinder is $0.16 \mathrm{~m}^{2}$. The void fraction of gas in a packed bed was assumed to be $40 \%$. The size of the pores in the bed are large compared to the mean free path of oxygen molecules. A tortuosity value of 3 was selected as conservative. The final value for the resistivity was estimated to be $R_{\text {Resin,o }} / c=0.615 \mathrm{hr} /$ liter.

The resistance of the NUCFLL to oxygen flow was based on a previously determined value for the resistance to diffusion of hydrogen. Resistance to diffusion of gas like oxygen through a NUCFIL is inversely proportional to the diffusivity of that gas through air. So, the $R_{\text {nucfli, } O_{2}} \approx R_{\text {nucfl, } H_{2}} \frac{D_{H_{2}}}{D_{\mathrm{O}_{2}}}$

The diffusivity of oxygen through air at $\mathrm{O}^{\circ} \mathrm{C}$ is $0.178 \mathrm{~cm}^{2} / \mathrm{s}$. The diffusivity of hydrogen through air at $\mathrm{O}^{\circ} \mathrm{C}$ is $0.634 \mathrm{~cm}^{2} / \mathrm{s}$. The resistance to diffusion of a NUCFIL was estimated to be $9.03 \mathrm{hr} /$ liter $^{5}$. So, assuming that the same modeling assumption apply to calculating the diffusion resistance of oxygen and hydrogen in a NUCFL, the resistance to diffusion for oxygen is $R_{\text {nucfll }, O_{2}} / c=32.2 \mathrm{hr} /$ liter.

The steady state value solution for the oxygen concentration is determined by setting the time derivatives in (1) and (2) to zero, and solving for the two oxygen mole fractions. Based on these values, the steady state oxygen mole fraction in an IXC is predicted to be $1.099 \%$ in the open volume and $0.0047 \%$ in pore space of the resin bed.

Before proceeding, note that the steady state oxygen concentrations predicted here are higher than observed in some IXM's. This is expected for two reasons. First, these predictions are based on conservatively low oxygen consumption rates; so they are inherently upper bounds. Second, IXC's contain smaller'volume of resin than IXM's, but both units are equipped with similar NUCFILs. This means that more oxygen is consumed in IXM's, while roughly comparable amounts of oxygen can enter. So, IXC's will tend to have higher oxygen mole fractions and lower hydrogen mole fractions than IXM's.

Transient values were determined by integrating the transient equation $\{1\}$ and $\{2\}$ using forward differencing. Time $t=\widehat{0} \overline{c o r r e s p o n d s}$ to the time when the unit is first drained and closed. At that time it is assumed that the oxygen mole fraction is atmospheric. The volume for each region in the IXC was assumed to be: Volume of gas in the open volume $V_{1}=106.5$ liters. Volume of gas in the resin pores $\mathrm{V}_{2}=56.6$ liters.

The transient behavior is illustrated in figure 2. It is evident from this figure that the oxygen mole fraction in an IXC reaches equilibrium very rapidly. The oxygen concentration falls below the flammability limit for oxygen in roughly $1 / 4$ a day. This is so rapid that there is probably significant error in the actual values as a function with time, because the transient begins before workers can cap the IXC. If $t=0$ is set as the time when the IXC is capped, the oxygen mole fraction certainly falls below the levels indicated on the figure. The steady-state values remain correct because they are unaffected by the initial condition.

Note: Those familiar with previous analysis will recall that the transients for hydrogen accumulation were slow ${ }^{6}$ relative to the time required for oxygen to reach equilibrium. The

5 Estimate of Hydrogen Concentration in KW-14, Jan, 26, 1995. LM Liljegren PNL IX-IR 0006.

${ }^{6}$ Need to flush LX'M's to Eliminate Hydrogen Gas. LM Liljegren June 13, 1995 


\section{Distribution}

No. of

Copies

\section{ONSITE}

18 Pacific Northwest National Laboratory

J. M. Bates (2)

L. M. Liljegren (5)

P. K. Melethil (2)

G. T. Terrones (2)

Information Release Office (7)
No. of

Copies

5 Westinghouse Hanford Company

C. DeFigh-Price (5)
X3-79
K7-15

K7-15

P7-22

K7-15

Distr.1 